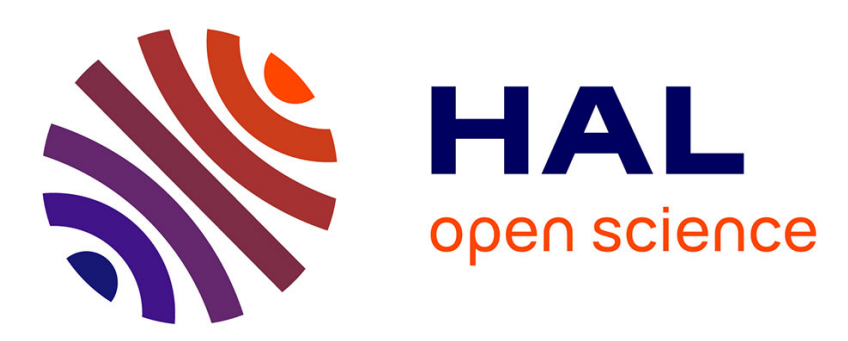

\title{
The association between hemispheric specialization for language production and for spatial attention depends on left-hand preference strength
}

Laure Zago, Laurent Petit, Emmanuel Mellet, Gaël Jobard, Fabrice Crivello, Marc Joliot, Bernard Mazoyer, Nathalie Tzourio-Mazoyer

\section{To cite this version:}

Laure Zago, Laurent Petit, Emmanuel Mellet, Gaël Jobard, Fabrice Crivello, et al.. The association between hemispheric specialization for language production and for spatial attention depends on left-hand preference strength. Neuropsychologia, 2015, 93, pp.394 - 406. 10.1016/j.neuropsychologia.2015.11.018 . hal-01382490

\author{
HAL Id: hal-01382490 \\ https://hal.science/hal-01382490
}

Submitted on 13 Nov 2020

HAL is a multi-disciplinary open access archive for the deposit and dissemination of scientific research documents, whether they are published or not. The documents may come from teaching and research institutions in France or abroad, or from public or private research centers.
L'archive ouverte pluridisciplinaire HAL, est destinée au dépôt et à la diffusion de documents scientifiques de niveau recherche, publiés ou non, émanant des établissements d'enseignement et de recherche français ou étrangers, des laboratoires publics ou privés. 


\title{
The association between hemispheric specialization for language production and for spatial attention depends on left-hand preference strength
}

\author{
Laure Zago $^{\text {a,b,c,*, Laurent Petit }}{ }^{\text {a,b,c, }}$, Emmanuel Mellet ${ }^{\text {a,b,c }}$, Gaël Jobard ${ }^{\text {a,b,c, }}$ \\ Fabrice Crivello $^{\text {a,b,c }}$, Marc Joliot ${ }^{\mathrm{a}, \mathrm{b}, \mathrm{c}}$, Bernard Mazoyer ${ }^{\mathrm{a}, \mathrm{b}, \mathrm{c}}$, Nathalie Tzourio-Mazoyer ${ }^{\mathrm{a}, \mathrm{b}, \mathrm{c}}$ \\ a CNRS, UMR 5296, Groupe d'Imagerie Neurofonctionnelle, Bordeaux, France \\ ${ }^{\mathrm{b}}$ CEA, UMR 5296, Groupe d'Imagerie Neurofonctionnelle, Bordeaux, France \\ ${ }^{\mathrm{C}}$ Université de Bordeaux, UMR 5296, Groupe d'Imagerie Neurofonctionnelle, Bordeaux, France
}

\section{A R T I C L E I N F O}

\section{Article history:}

Received 18 June 2015

Received in revised form

16 October 2015

Accepted 23 November 2015

Available online 25 November 2015

Keywords:

Cerebral asymmetry

Handedness

Cognitive function

Pseudoneglect

\begin{abstract}
A B S T R A C T
Cerebral lateralization for language production and spatial attention and their relationships with manual preference strength (MPS) were assessed in a sample of 293 healthy volunteers, including 151 lefthanders, using fMRI during covert sentence production (PROD) and line bisection judgment (LBJ) tasks, as compared to high- and low-level reference tasks. At the group level, we found the expected complementary hemispheric specialization (HS) with leftward asymmetries for PROD within frontal and temporal regions and rightward asymmetries for LBJ within frontal and posterior occipito-parietotemporal regions. Individual hemispheric (HLI) and regional (frontal and occipital) lateralization indices (LI) were then calculated on the activation maps for PROD and LBJ. We found a correlation between the degree of rightward cerebral asymmetry and the leftward behavioral attentional bias recorded during LBJ task. This correlation was found when LBJ-LI was computed over the hemispheres, in the frontal lobes, but not in the occipital lobes. We then investigated whether language production and spatial attention cerebral lateralization relate to each other, and whether manual preference was a variable that impacted the complementary HS of these functions. No correlation was found between spatial and language LIs in the majority of our sample of participants, including right-handers with a strong right-hand preference ( $\mathrm{sRH}, n=97$ ) and mixed-handers ( $\mathrm{MH}, n=97$ ), indicating that these functions lateralized independently. By contrast, in the group of left-handers with a strong left-hand preference (sLH, $n=99$ ), a negative correlation was found between language and spatial lateralization. This negative correlation was found when LBJ-LI and PROD-LI were computed over the hemispheres, in the frontal lobes and between the occipital lobes for LBJ and the frontal lobes for PROD. These findings underline the importance to include sLH in the study sample to reveal the underlying mechanisms of complementary HS.
\end{abstract}

(c) 2015 Elsevier Ltd. All rights reserved.

\section{Introduction}

Hemispheric specialization (HS) is a fundamental principle in the functional organization of the human brain (Hervé et al., 2013). In more than $90 \%$ of humans, the left hemisphere is specialized for language and the motor control of their dominant hand, whereas the right hemisphere is more dedicated to the control of visuospatial skills including spatial attention. This complementary hemispheric pattern between the language and spatial domain prevailing in the population probably results from evolutionary

\footnotetext{
* Correspondence to: UMR 5296, Case 71, Université de Bordeaux, PAC Carreire, 146, rue Léo Saignat, CS 61292, 33076 Bordeaux Cedex, France.

E-mail address: laure.zago@u-bordeaux.fr (L. Zago).
}

adaptive processes and selection pressure (Hopkins and Cantalupo, 2008; Hutsler et al., 2002). Different mechanisms have been suggested to account for HS, most of them emphasizing a major role of the corpus callosum in the development and maintenance of hemispheric asymmetry. For example, Gazzaniga (2000) suggested that once considering the corpus callosum as the great communication link, a pre-existing system (i.e, perceptual function) could be jettisoned as new functions (language) developed in one hemisphere, while the other hemisphere could continue to perform the previous functions for both half-brains (Gazzaniga, 2000). Thus, it allowed the development of new competences by saving brain space through reduced redundancy.

Two questions remain largely unresolved: how do the lateralized functions of the two hemispheres relate and what is the nature (biologic, genetic and/or environmental) of the 
mechanisms underlying cerebral asymmetries. Bryden proposed two accounts for the way in which the functions of the two hemispheres are related to one another (Bryden, 1990; Bryden et al., 1983). The first one called causal complementarity considers that the division of functions between hemispheres is causally related, with right hemisphere dominance for spatial functions as a consequence of left-hemispheric involvement with language. In that case, causal complementarity predicts that people who show left-hemisphere lateralization for a verbal task should show righthemisphere lateralization for spatial tasks, and those few who show right-hemisphere lateralization for verbal tasks should also show left-hemisphere effects for spatial ones (mirror-reversed lateralization). In the literature, the causal hypothesis has been evaluated either by looking for by negative correlations between the degree of lateralization of verbal and spatial tasks (BadzakovaTrajkov et al., 2010; Cai et al., 2013; Whitehouse and Bishop, 2009) or by searching whether the functions always dissociate between hemispheres (Flöel et al., 2001). The second account of complementarity is called statistical or independent complementarity and considers that the asymmetries of language and visuospatial functions are independently determined. Although a bias for language to be left-lateralized and visuospatial skills to be right-lateralized does exit in the population, it would simply reflect probabilities relating to independent underlying mechanisms. The independent complementarity predicts the existence of all possible patterns of HS (albeit in different proportions) for language and spatial functions and an absence of correlation between verbal and nonverbal asymmetries, since the atypical lateralization of one function has no consequence for the lateralization of the other functions. In that case, language and spatial functions can be specialized within the same hemisphere (Flöel et al., 2005).

Until recently, the majority of studies favored an independent complementary HS of language and spatial functions. Using the functional Transcranial Doppler ultrasound (fTCD) imaging technique, several studies reported the existence of almost all combinations of cerebral lateralizations for verbal and spatial functions at the individual level (Flöel et al., 2005, 2001; Powell et al., 2012; Whitehouse and Bishop, 2009), speaking against the prediction of the causal account. Moreover, an absence of negative correlation between language and spatial lateralization has been observed in right-handed participants (Dorst et al., 2008; Lust et al., 2011; Rosch et al., 2012). Opposite results have been obtained by Badzakova-Trajkov et al. (2010) with functional magnetic resonance imaging (fMRI)-based indices of regional asymmetry in a sample of 155 participants including 48 left-handers (Badzakova-Trajkov et al., 2010). They evidenced negative correlations between left frontal-lobe asymmetry for word generation and both right temporal-lobe asymmetry for face processing and right parietal lobe asymmetry for visuospatial landmark task, supporting a causal relationship between the regional specialization of language, and face processing / spatial attention functions. More recently, Cai et al. (2013) specifically investigated the lateralization of spatial attention in participants with atypical right-lateralized speech dominance (Cai et al., 2013). They found that the 13 left-handers who showed atypical right-hemispheric lateralization of the inferior frontal area during a word generation task presented a leftward lateralization for spatial attention in a parietal region. By contrast, among the 16 left-handers typical for language lateralization, all but one were right-lateralized for spatial attention. The authors concluded that, in left-handers, both lateralizations are dependent, and that the spatial function also lateralize atypically when language is atypically represented.

Interestingly, these recent fMRI studies that demonstrated a relation between language and spatial lateralization all included an important number of left-handers. Manual preference could be a factor that impacts the complementary HS of language and spatial functions. Badzakova-Trajkov et al. (2010) indeed showed that handedness is associated with frontal-lobe asymmetry during word production, but not with parietal-lobe asymmetry during landmark task (Badzakova-Trajkov et al., 2010). Moreover, we recently demonstrated that the rare category of right dominant individuals for language, corresponding to $0.6 \%$ of the general population, is composed exclusively of strong left-handers (Mazoyer et al., 2014). The proportion of left-handers included in the studies could be a major component explaining the contradictory results present in the literature. One hypothesis stemming from these observations would be that the left-handed population may obey to different rules of complementary HS in comparison with righthanders.

To test this hypothesis, we investigated how lateralized functions such as language production and spatial attention relate to each other in a large cohort of 293 healthy participants. To address the effect of manual preference on complementary HS, this cohort included 152 left-handers to cover the spectrum of cerebral lateralization and to maximize the chances of including atypical cerebral lateralizations (Cai and Van der Haegen, 2015; Willems et al., 2014). Manual preference was evaluated with a modified version of the Edinburgh questionnaire (Mazoyer et al., 2014; Oldfield, 1971). To take into account both the strength and the direction of manual preference as recommended by some authors (Corballis 2009; Ocklenburg et al., 2014a), the population was divided in three groups of strong left-, strong right-, and mixedhanded participants. Language lateralization was assessed with a covert sentence production task (Mazoyer et al., 2014) while spatial attention lateralization was assessed with a line bisection judgment, a modified version of the landmark task. These two tasks are considered as experimental paradigms suited to measure language (Dym et al., 2011) and spatial attention (Jansen et al., 2004) dominances, respectively.

\section{Methods and Materials}

\subsection{Participants}

Two hundred and ninety three healthy volunteers (151 men, 142 women; age, 18-57 y; mean age, 25.2 y, S.D. $=6.4$ y) participated to the study. All were recruited within the framework of the BIL\&GIN, a multimodal imaging/psychometric/genetic database specifically designed for studying the structural and functional neural correlates of cerebral lateralization (Mazoyer et al., 2015). Note that these 293 participants were included in the study of Mazoyer et al. (2014). Among the 293 subjects, 142 declared themselves as right-hander ( $\mathrm{RH}, 70$ women, 72 men) and 151 as left-hander ( $\mathrm{LH}, 72$ women, 79 men). The mean level of education was 15.5 years \pm 2.3 y (range: $11-20$ ) that corresponded to approximately 3 years of education after the French baccalaureate. The local ethics committee (CCPRB Basse-Normandie) approved the experimental protocol. The participants provided written, informed consent and received compensation for their participation. All participants were free of brain abnormalities, as assessed via inspection of their structural T1-MRI scans by a neuroradiologist. All had normal or corrected-to-normal vision.

\subsection{Manual preference strength (MPS)}

MPS was quantified using the score at Edinburgh Handedness Inventory (Oldfield 1971), a series of 10 items dealing with subject-preferred hand for manipulating objects and tools. In the present study, we only used 9 of these 10 items, dropping the "broom" item since very few young people had enough familiarity with this tool. MPS values ranged from -100 for strong left- 
handedness to +100 for strong right-handedness. Due to the J-shape distribution of EHI scores, MPS was transformed as a 3-level ordinal variable with thresholds as close as possible to the 1st and 2nd terciles of MPS distribution (see Mazoyer et al., 2014 for details; Ocklenburg et al., 2014b). The boundaries were [ -100 , -55] for strong LH (sLH), [-54, +98] for mixed-hander (MH, corresponding to weak left-handers and weak right-handers), and $[+99,+100]$ for strong $\mathrm{RH}(\mathrm{sRH})$. According to this tercile repartition, 99 participants were classified as SLH (mean MPS \pm SD; $-88 \pm 14$; 44 females), 97 were classified as MH ( $27 \pm 54$; 48 females), and 97 as sRH (50 females). In the MH group, 45 subjects considered themselves as right-handers and 52 as left-handers.

\section{3. fMRI tasks}

All the fMRI tasks of the BIL\&GIN database are fully described elsewhere (Mazoyer et al., 2015). Here, we will describe only those used in this study.

\subsubsection{Language production}

To evaluate the lateralization of language production, we used a sentence production task $\left(\mathrm{PROD}_{\mathrm{SENT}}\right)$. Subjects were presented with white line drawing pictures on a black screen which were either cartoons depicting a scene involving characters, or a scrambled version of these pictures. Pictures covered a $14^{\circ} \times 14^{\circ}$ visual area and were presented for $1 \mathrm{~s}$. Right after the presentation of a picture, subjects had to covertly generate either a sentence $\left(\right.$ PROD $_{\text {SENT }}$ ) when they saw a cartoon, or to enunciate the ordered list of the months of the year (PROD $\left.{ }_{\text {LIST }}\right)$ when they saw a scrambled picture. For PROD $_{\text {SENT, }}$, subjects were instructed to produce sentences that all had the same structure; the sentences were to start with a subject and its adjective, followed by a verb that described the action taking place, and were to end with an-

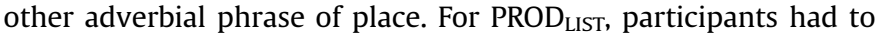
covertly recite the ordered list of months of the year and to press the pad when they had finished. During these PROD PROD ${ }_{\text {LIST }}$ periods, participants had to fixate a white-cross displayed at the center of the screen and to press the pad with their index finger when they had. A low-level visuo-motor baseline followed each event $\left(\right.$ PROD $_{\text {SENT }}$ or PROD $_{\text {LIST }}$ ) during which a fixation cross appeared on the screen and the participant had to press a button when the fixation cross was switched to a square. This second part of the trial aimed at refocusing the participant attention on a non-verbal stimulus and to control for the manual motor response. Each trial was $18 \mathrm{sec}$ long, the time limit for response being $9 \mathrm{~s}$ including the 1-s picture display, and at least $9 \mathrm{~s}$ of low-level fixation (details are given in Mazoyer et al. 2014).

A 12-sec presentation of a fixation crosshair preceded and followed the first and last trials of each run. This slow event-related experimental paradigm randomly alternated 10 trials of sentence generation with 10 trials of recitation of a list of months. The response time for reciting each list of words or generating each sentence was recorded using a fiber optic pad.

\subsubsection{Spatial attention}

To evaluate the lateralization of spatial attention, we used a line bisection judgment task (LBJ). The LBJ consisted in 2-s presentation of a horizontal line bisected by a short vertical line (subtending a visual angle of $1^{\circ}$ ), followed by an 10-s delay, during which only a fixation cross appeared on the screen. Participants were asked to decide whether the bisection mark was at the center of the horizontal line, or slightly deviated to the left or to the right of the center. They responded by pressing a three-buttons response pad, with the right index finger for answering "left", the right middle finger for answering "middle", and the right ring finger for answering "right". Note that LH subjects were free to choose the hand they preferred for using the response pad, 133 used their right-hand and 18 used their left-hand (including 5 women). For these 18 participants, the ring finger indicated "left", the middle finger "middle" and the index finger "right". The horizontal lines were displayed at three different positions along the horizontal axis $\left(-7^{\circ}, 0^{\circ}\right.$ or $+7^{\circ}$ of the center of the screen) with three different lengths $\left(6^{\circ}, 7^{\circ}\right.$ or $9^{\circ}$ of visual angle). The bisection mark was deviated of $0.3^{\circ}$ on the left or on the right of the center. All parameters were counterbalanced. 36 trials were presented with an equal number of centered-, leftward-, and rightward-bisected trials. A 12-s presentation of a fixation cross preceded and followed the first and last trial, respectively. A practice phase was run outside the scanner.

LBJ task was compared to a visually-guided saccades task (VGS) that was performed by the same subjects in an other run (see Mazoyer et al. 2015 for details). This run consisted in four 16-s blocks of visually-guided saccadic eye movements alternated with four 16-s blocks of central fixation crosshair. The subject performed visually-guided saccades toward a white visual dot. The dot $\left(0.4^{\circ}\right)$ was first displayed at the primary central eye position and then jumped randomly for $16 \mathrm{~s}$ to different eccentric positions along the horizontal axis, with a frequency of $1.25 \mathrm{~Hz}$. The numbers of left and right saccades were equated with average amplitude in both directions of $6.5^{\circ}$ (range, $3-10^{\circ}$ ).

\subsection{Behavioral recordings}

The behavioral parameters are given in Table 1 .

\subsubsection{Language task}

Immediately after the session, the participants were asked to recall each sentence they covertly generated during the fMRI session with the support of the pictures they had viewed. This approach enabled the evaluation of the average number of words of the covertly generated sentences for each participant.

\subsubsection{Spatial task}

Participant's correct response time (correct RTs) and accuracy (\% correct) were recorded. To evaluate a spatial bias, we compared the number of incorrect rightward and leftward deviated responses. Rightward deviated responses corresponded to the responses for which the subject answered "right" or "middle" for left bisected trials and "right" for centered bisected trials. Leftward deviated response included the responses for which the subject responded "left" or "middle" for right bisected trials, and "left" for centered bisected trials. An individual spatial response bias was calculated based on deviated responses produced by the participant with the following formula: (rightward - leftward deviated responses) / (leftward + rightward deviated responses). This index gave negative values when responses were more deviated towards the left than the right (leftward bias), positive values when the opposite was true (rightward bias).

\subsection{Images acquisition}

Imaging was performed on a Philips Achieva 3Tesla MRI scanner. Structural MRI protocols consisted in a localizer scan, a high resolution $3 \mathrm{D} \quad \mathrm{T}_{1}$-weighted volume acquisition $(\mathrm{TR}=20 \mathrm{~ms}$; $\mathrm{TE}=4.6 \mathrm{~ms}$; flip angle $=10^{\circ}$; inversion time $=800 \mathrm{~ms}$; turbo field echo factor $=65$; sense factor $=2$; matrix size $=256 \times 56 \times 180$; $1 \mathrm{~mm}^{3}$ isotropic voxel size) and a $T_{2}^{*}$-weighted multi-slice acquisition $\left(\mathrm{T}_{2}^{*}\right.$-FFE sequence, $\mathrm{TR}=3.500 \mathrm{~ms} ; \mathrm{TE}=35 \mathrm{~ms}$; flip angle $=90^{\circ}$; sense factor $=2 ; 70$ axial slices; $2 \mathrm{~mm}^{3}$ isotropic voxel size). Functional images were acquired with a whole-brain $\mathrm{T}_{2}^{*}$-weighted echo planar imaging acquisition $\left(\mathrm{T}_{2}^{*}\right.$-EPI, $\mathrm{TR}=2 \mathrm{~s}$; $\mathrm{TE}=35 \mathrm{~ms}$; flip angle $=80^{\circ} ; 31$ axial slices; $3.75 \mathrm{~mm}^{3}$ isotropic 
voxel size) covering the same field of view than the $T_{2}^{*}$-FFE acquisition. The first four volumes of each sequence were discarded to allow for stabilization of the MR signal.

\subsection{Image analysis}

Preprocessing was based on Statistical Parametric Mapping subroutines (SPM5; http://www.fil.ion.ucl.ac.uk/ spm). Anatomical T1-weighted volumes were spatially normalized by aligning individual anatomical volumes to specific cerebral tissue templates built from the T1 images of 80 right-handed subjects ( 40 men) acquired with the same scanner and acquisition parameters. Spatial normalization parameters were set to their SPM5 default values, providing for each subject a 3D, spatially normalized deformation field of T1 images into the Montreal Neurological Institute (MNI) reference space. Each functional run was corrected for slice timing and motion and registered onto the $\mathrm{T}_{2}^{*}$-FFE volume. Combining the $\mathrm{T}_{2}^{*}$-FFE to T1-weighted registration parameters and the spatial normalization parameters, functional images were resampled into the $2 \times 2 \times 2 \mathrm{~mm}^{3}$ template space and spatially smoothed (Gaussian $6 \mathrm{~mm}^{3}$ full width at half maximum filter).

For each participant, four SPM contrast maps were computed

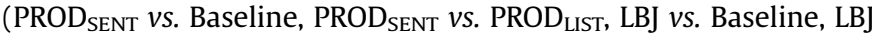
$v s$. VGS). Left or right motor region was excluded from LBJ contrast maps to parse out activity arising from hand-related responses during LBJ task. Delineation of motor left and right region was based on the t-statistical BOLD activation map (threshold set at $t=13$ ) obtained during a left or right finger-tapping task on a group of 268 participants (all included in the present study sample) of the BIL\&GIN database (Tzourio-Mazoyer et al., 2015).

\subsubsection{Voxel-based functional asymmetry analysis}

The functional asymmetry patterns of activation for language production and spatial attention were investigated with a voxelbased functional asymmetry analysis of the BOLD signal in SPM. Asymmetries were obtained by comparing BOLD value of one voxel of one hemisphere to the same voxel of the other hemisphere, for each participant and for each task PROD $_{\text {SENT }}$, PROD ${ }_{\text {LIST, }}$ LBJ and VGS). To do so, left/right flipped maps were computed (along the inter-hemispheric fissure; i.e., MNI stereotaxic $\mathrm{x}=0$ plane mirror images) resulting in individual BOLD and flippedBOLD maps. The asymmetry patterns were reported for PROD SENT $_{\text {S }}$

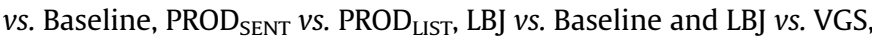
with thresholds set to $p<0.05$ corrected for family-wise error (FWE). Activation foci were labeled using automatic anatomical labeling software (AAL, Tzourio-Mazoyer et al., 2002) and reported in Table 2.

\subsubsection{Individual lateralization indices (LI)}

For each individual, hemispheric (HLI) and regional (RLI) lateralization indices were computed using the LI-toolbox (Wilke and Schmithorst, 2006) with a bootstrapping method (Wilke and Lidzba, 2007). This method involved the calculation of 20 equally sized thresholds from 0 to the maximum $t$ value. At each threshold, 100 bootstrapped samples with a resampling ratio of $k=0.25$ were taken on the left and right hemisphere. All 10,000 possible LI combinations were then calculated from these samples for surviving voxels on the left and the right, with the formula $[(L-R) /(L+R)]$. The $25 \%$ highest and lowest values were excluded from the analysis (considered as outliers) and the remaining LI were averaged to compute an individual LI index for each t-map. LI yielded values between -100 (complete right lateralization) and +100 (complete left lateralization).

HLIs were computed within the (grey and white) anatomical template mask used for the fMRI data normalization, excluding the cerebellum. HLIs were computed for the 4 individual t-maps $\left(\mathrm{PROD}_{\mathrm{SENT}}\right.$ vs. Baseline; $\mathrm{PROD}_{\mathrm{SENT}}$ vs. PROD $_{\mathrm{LIST}}$; LBJ vs. Baseline; LBJ vs. VGS).

RLIs were calculated within particular regions of interest (ROIs) that were pre-defined in the LI-toolbox and on specific t-maps. For language production, RLI was computed within frontal ROI for

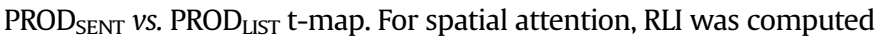
within frontal and occipital ROIs for LBJ vs. Baseline t-map. These ROIs were chosen because they were the most asymmetric regions in the current study and were consistent with previous studies (Badzakova-Trajkov et al. 2010; Cai et al., 2013; Rorden et al. 2006). HLI and RLI values are reported in Table 3 on the whole sample $(n=293)$, and according to MPS (sLH, MH, sRH) groups.

\subsection{Statistical analyses}

Unless otherwise specified, all statistical procedures were conducted using the JMP10 software package, (www.jmp.com, SAS Institute Inc., 2012).

\subsubsection{Task performance}

We verified whether performance obtained during language and spatial tasks depended or not on MPS or Sex. Separate ANOVAs were conducted with MPS (sLH, MH, sRH) and Sex as betweensubject factors, and their interaction on the different behavioral recordings such as the number of words per sentence and the response times for language production tasks, the \% correct, the correct response time and the spatial bias for LBJ.

\subsubsection{Effect of control condition on language and spatial hemi- spheric LIs}

This analysis was done to assess the effect of the control condition (high vs. low level) on the HLIs, and to test whether this

Table 1

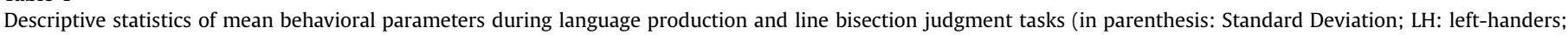
$\mathrm{RH}$ : right-handers; sLH: strong left-handers; $\mathrm{MH}$ : mixed handers; sRH: strong right-handers).

\begin{tabular}{|c|c|c|c|c|c|c|}
\hline & \multirow{2}{*}{$\begin{array}{l}\text { All subjects } \\
(N=293)\end{array}$} & \multicolumn{2}{|c|}{ Self-reported Handedness } & \multicolumn{3}{|c|}{ Manual preference strength } \\
\hline & & $\mathbf{L H}(N=151)$ & $\mathbf{R H}(N=142)$ & $\mathbf{~} \mathbf{L H}(N=99)$ & $\mathbf{M H}(N=97)$ & sRH $(N=97)$ \\
\hline \multicolumn{7}{|l|}{ Language production } \\
\hline Words per sentence & $12.3(2.0)$ & $12.5(2.0)$ & $12.2(1.9)$ & $12.7(2.1)$ & $12.4(2.1)$ & $12.0(1.8)$ \\
\hline Sentence prod RT (ms) & $5608.2(941.2)$ & $5610.2(926.6)$ & $5606.0(959.7)$ & $5668.8(878.1)$ & $5557.6(1017.9)$ & $5598.4(935.5)$ \\
\hline Word-List prod RT (ms) & $5230.2(1134.2)$ & $5208.4(1176.7)$ & $5253.3(1090.9)$ & $5223.0(1201.8)$ & $5216.8(1186.7)$ & $5250.8(1021.6)$ \\
\hline \multicolumn{7}{|l|}{ Line bisection judgment } \\
\hline$\%$ correct & $84.2(10.9)$ & $84.1(11.3)$ & $84.3(10.5)$ & $86.1(9.5)$ & $83.0(10.9)$ & $83.9(10.5)$ \\
\hline $\mathrm{RT}(\mathrm{ms})$ & $1125(141.0)$ & $1127.9(142.1)$ & $1122.6(140.4)$ & $1121.9(142.0)$ & $1130.1(144.4)$ & $1124.1(138.0)$ \\
\hline Spatial response bias (R-L) & $-0.08(0.18)$ & $-0.06(0.18)$ & $-0.09(0.18)$ & $-0.05(0.16)$ & $-0.10(0.18)$ & $-0.09(0.18)$ \\
\hline
\end{tabular}


Table 2

Asymmetry maps during spatial and language tasks. The statistical threshold is set to $p<0.05$ corrected for family-wise error (FWE; L: left; R: right; ant: anterior; post: posterior; LBJ: line bisection judgment; VGS: visually-guided saccades;

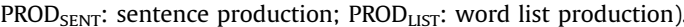

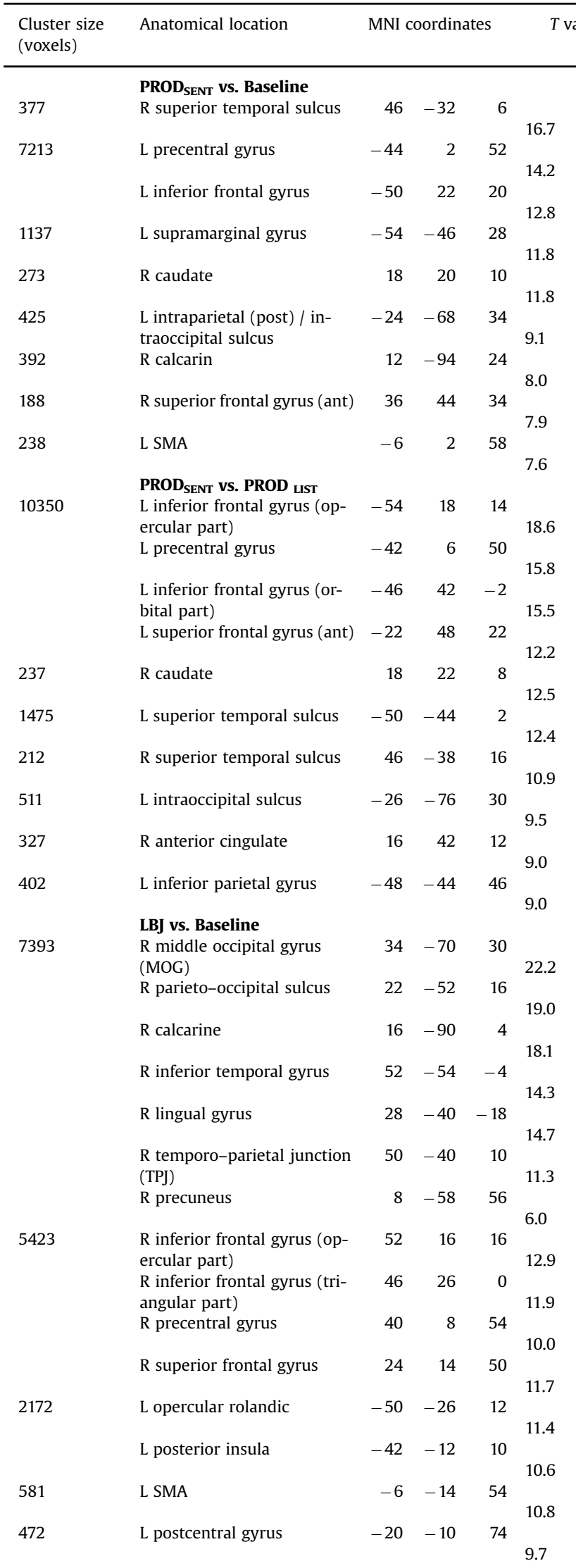

Table 2 (continued)

\begin{tabular}{|c|c|c|c|c|c|}
\hline \multirow{2}{*}{$\begin{array}{l}\text { Cluster size } \\
\text { (voxels) }\end{array}$} & \multirow[t]{2}{*}{ Anatomical location } & \multicolumn{3}{|c|}{ MNI coordinates } & \multirow[t]{2}{*}{$T$ value } \\
\hline & & & & & \\
\hline \multirow[t]{5}{*}{5751} & R MOG & 34 & -70 & 28 & \\
\hline & & & & & 16.0 \\
\hline & $\mathrm{R}$ parieto-occipital sulcus & 24 & -56 & 14 & \\
\hline & R fusiform & 36 & -80 & 6 & 14.4 \\
\hline & & & & & 14.2 \\
\hline \multirow[t]{4}{*}{2178} & L postcentral gyrus & -54 & -24 & 12 & \\
\hline & & & & & 10.7 \\
\hline & L opercular rolandic & -34 & -36 & 14 & \\
\hline & & & & & 12.5 \\
\hline \multirow[t]{2}{*}{4097} & $\begin{array}{l}\mathrm{R} \text { inferior frontal gyrus (op- } \\
\text { ercular part) }\end{array}$ & 54 & 18 & 16 & 10.7 \\
\hline & $\begin{array}{l}\mathrm{R} \text { inferior frontal gyrus (tri- } \\
\text { angular part) }\end{array}$ & 44 & 28 & -4 & 10.7 \\
\hline 494 & L SMA & -6 & -14 & 52 & 10.6 \\
\hline 353 & $\begin{array}{l}\text { R superior temporal sulcus } \\
\text { (post) }\end{array}$ & 48 & -24 & -6 & 8.8 \\
\hline 435 & L postcentral gyrus & -20 & -10 & 74 & 88 \\
\hline 546 & $\mathrm{R}$ median frontal gyrus & 6 & 22 & 50 & 8.5 \\
\hline
\end{tabular}

Table 3

Descriptive statistics of mean lateralization index (LI) for language production and spatial attention tasks at the hemisphere (HLI) and regional (RLI) levels. LI values are given for the total sample of participants, and detailed for manual preference strength (sLH: strong left-handers; MH: mixed-handers; sRH: strong right-handers; in parenthesis: standard deviation; LBJ: line bisection judgment; VGS: visually-guided saccades; PROD ${ }_{\text {SENT }}$ : sentence production; PROD $_{\text {LIST: word list }}$ production).

\begin{tabular}{|c|c|c|c|c|}
\hline & \multirow{2}{*}{$\begin{array}{l}\text { All subjects } \\
(293)\end{array}$} & \multicolumn{3}{|c|}{ Manual preference strength } \\
\hline & & sLH (99) & MH (97) & sRH (97) \\
\hline \multicolumn{5}{|l|}{$\begin{array}{l}\text { Language } \\
\text { production }\end{array}$} \\
\hline $\begin{array}{l}\text { HLI for PROD } \\
\text { vs. Baseline }\end{array}$ & $34.8(29.1)$ & $32.3(32.0)$ & $34.0(28.6)$ & $38.0(26.5)$ \\
\hline $\begin{array}{l}\text { HLI for } \text { PROD }_{\text {SENT }} \\
\text { vs. PROD }\end{array}$ & $47.9(33.4)$ & $38.4(43.7)$ & $53.5(27.0)$ & $51.9(23.9)$ \\
\hline PROD-Frontal-LI & $58.2(35.3)$ & $46.2(48.3)$ & $61.8(27.7)$ & $66.8(20.2)$ \\
\hline \multicolumn{5}{|l|}{ Spatial Attention } \\
\hline $\begin{array}{l}\text { HLI for LBJ vs. } \\
\text { Baseline }\end{array}$ & $-20.4(23.4)$ & $-18.0(26.2)$ & $-24.5(20.7)$ & $-18.4(22.5)$ \\
\hline HLI for LBJ $v s$. VGS & $-19.2(29.0)$ & $-12.0(29.3)$ & $-22.9(27.7)$ & $-23.1(28.9)$ \\
\hline LBJ-Frontal-LI & $-20.9(27.9)$ & $-19.3(30.4)$ & $-24.6(27.1)$ & $-18.8(25.8)$ \\
\hline LBJ-Occ-LI & $-15.4(27.8)$ & $-11.6(29.7)$ & $-19.9(27.6)$ & $-14.9(25.4)$ \\
\hline
\end{tabular}

effect was similar on the two functions (PROD and LBJ). The second objective was to select the comparisons that will maximize the lateralized activity for language production ( $\mathrm{PROD}_{\text {SENT }} v s$. Baseline or PROD ${ }_{\text {SENT }} v s$. PROD $_{\text {LIST }}$ ) and spatial attention (LBJ vs. Baseline or LBJ $v s$. VGS) on which the further analyses will be performed. We performed an ANOVA on HLIs with Control condition (2 levels: Low, High), Function (2 levels: Production, Spatial attention) and their interaction (Control x Function) as within-subject factors.

\subsubsection{Relationships between spatial attention, language production} LIs, MPS and spatial bias

The following analyses were performed with the $R$ 3.2.2 software ( $R$ foundation for statistical computations, Vienna, Austria).

2.7.3.1. Hemispheric LIs. We performed an ANCOVA to investigate whether: 1) there was a relationship between spatial attention 
A
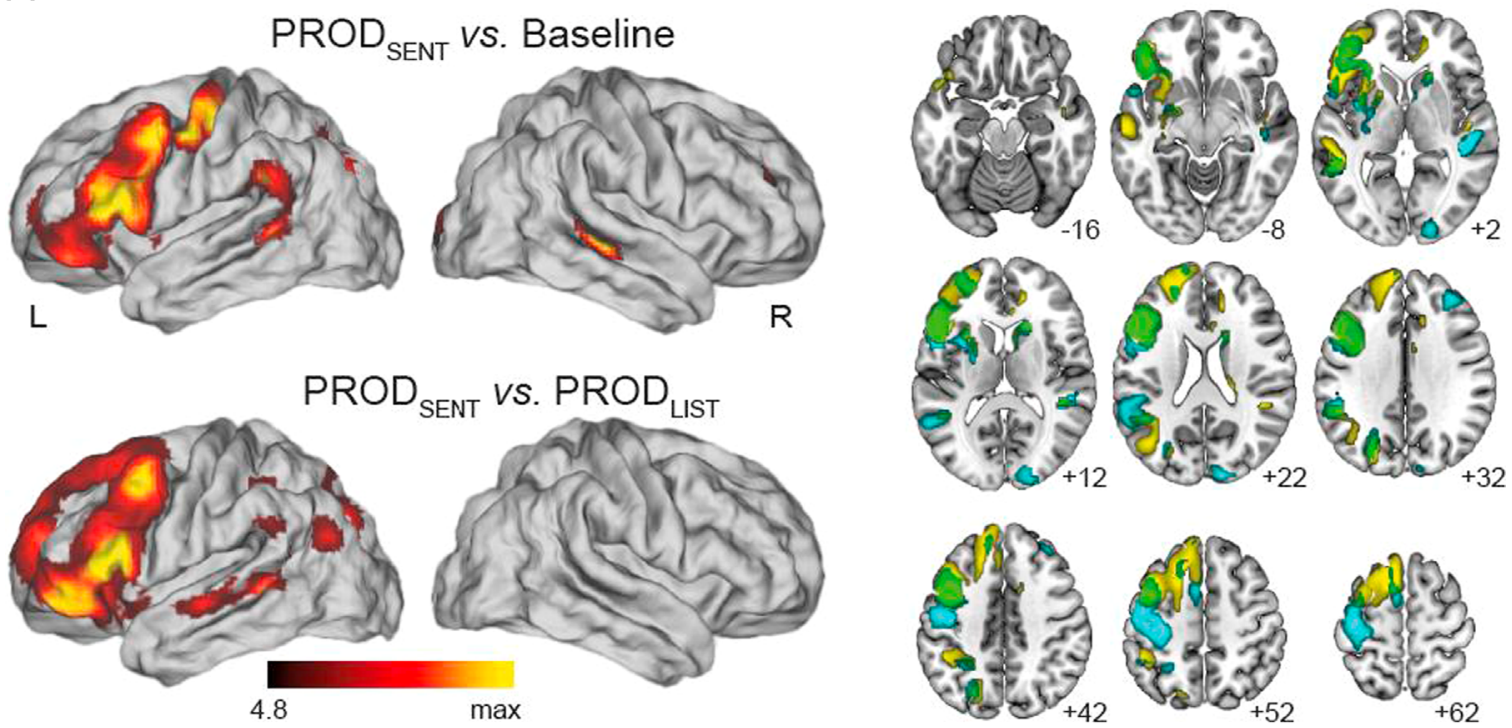

B
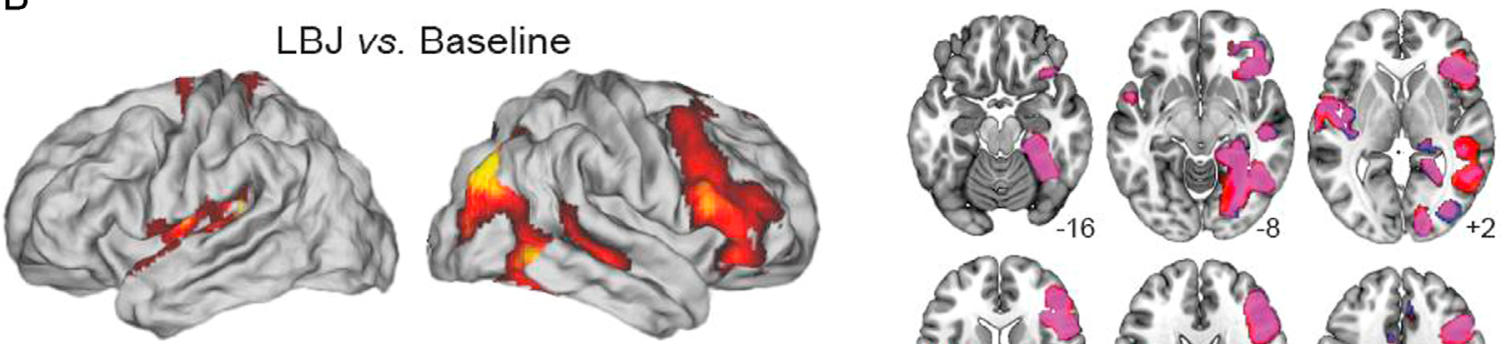

LBJ vs. VGS
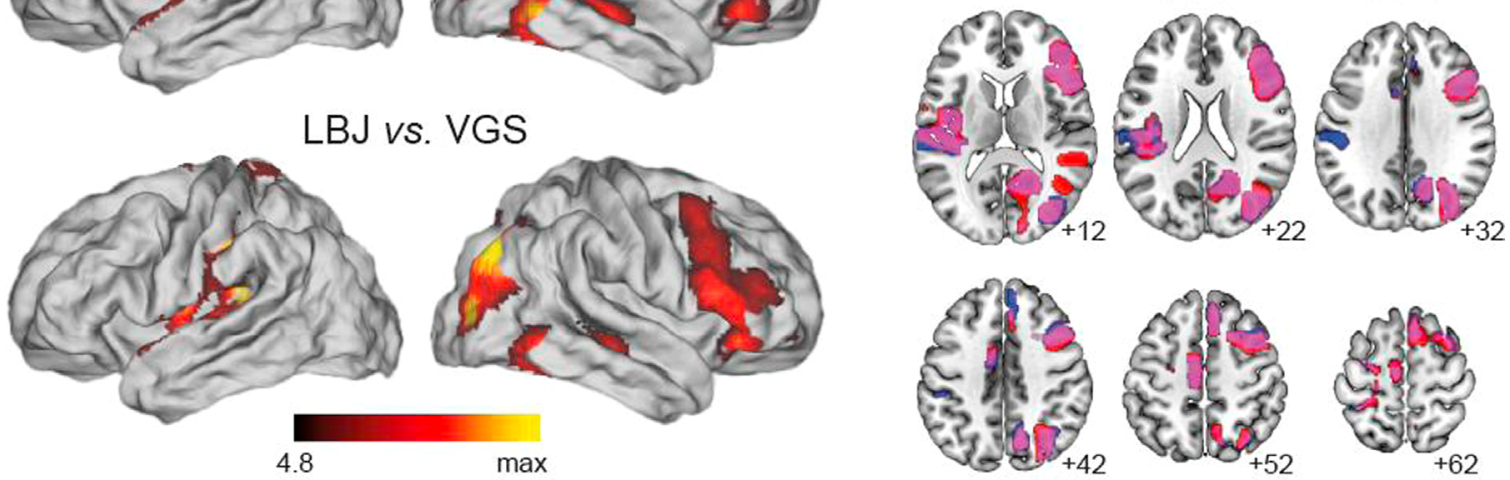

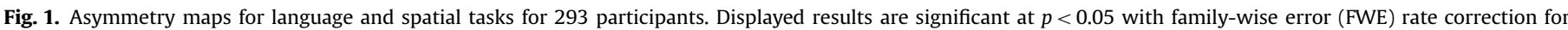

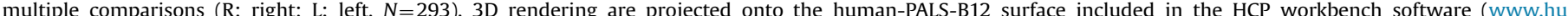

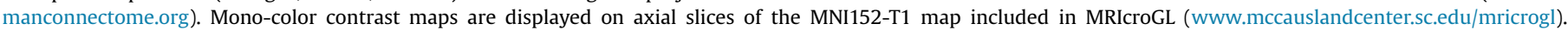

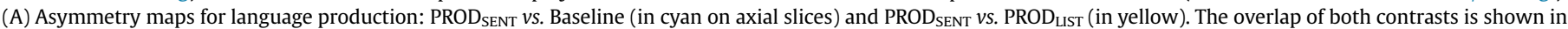

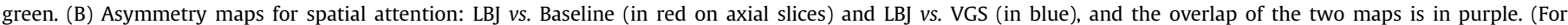
interpretation of the references to color in this figure legend, the reader is referred to the web version of this article.)

and language production HLIs, and whether this relationship varied according to MPS; 2) there was a relationship between the degree of asymmetry in spatial attention and the degree of pseudoneglect as assessed with the spatial response bias; and 3) there was an effect of sex on the degree of asymmetry in spatial attention. The ANCOVA was performed on LBJ-HLI values, with MPS and Sex as between-subject variables, and PROD-HLI and spatial bias as within-subject standardized covariates, including PROD-HLI $\times$ MPS interaction. Post-hoc analyses (Holm-Bonferroni corrected $p$-values) were performed on the interaction to evaluate the slope of regression between LBJ-HLI and PROD-HLI of each MPS group, as well as the differences between MPS groups.

2.7.3.2. Regional LIs. We investigated whether there was a relationship between spatial attention and language production within ROIs. Two separate ANCOVAs were performed using the same model as before (MPS, Sex, PROD-Frontal-LI, spatial bias, PROD-Frontal-LI $\times$ MPS interaction). One was performed on the LBJ-LI values computed within the frontal region (LBJ-Frontal-LI), the other within the occipital region (LBJ-Occ-LI). Here again, posthoc analyses (Holm-Bonferroni corrected $p$-values) were performed on the interaction to evaluate the slope of regression between LBJ-HLI and PROD-HLI of each MPS group as well as the differences between MPS groups.

2.7.4. Effect of strong atypical language right dominant subjects on the relationship between spatial attention and language production LIs

As strong left-handers are known to gather together the most atypical language dominant subjects, we investigated whether the relationship between language and spatial functions could be due to atypically right-lateralized individuals for language production. 
To categorize right language dominant subjects, we used the same threshold that we used in our previous study on language production (Mazoyer et al. 2014) with a $\mathrm{LI}<-50$. These strong atypical individuals were removed of the analysis and the abovementioned ANCOVA model was performed again at the hemispheric and regional levels.

\section{Results}

\subsection{Tasks performance}

\subsubsection{Language}

On average, participants took $5.6 \pm 0.9 \mathrm{~s}$ (mean \pm SD) to covertly produce a sentence, and $5.2 \pm 1.1 \mathrm{~s}$ to covertly enounce the list of the months (paired $t(292)=5.7 p<0.0001$ ). The average number of words per generated sentence was $12.3 \pm 2.0$ words (Table 1). The ANOVAs revealed no effect of MPS, Sex or MPS x Sex interaction on number of words per sentence $(F(5,286)=1.2$, $p=0.3)$ and response times for sentence $(F(5,286)=0.8, p=0.5)$ and word-list production $(F(5,286)=0.5, p=0.8)$ tasks.

\subsection{2. $L B J$}

Performance during LBJ was high $(84.2 \pm 10.9)$ and participants globally responded in $1.1 \pm 0.14 \mathrm{~s}$. No effect of MPS, Sex or MPS $\times$ Sex interaction was found on both \% correct $(F(5,286)=1.5, p=0.1)$ and RTs $(F(5,286)=0.4, p=0.8)$. At the group level, the participants exhibited a leftward response bias during the LBJ task (mean response bias $=-0.08 \pm 0.18$; one sample $t$-test to $0, \mathrm{t}(292)=-7.4$, $p<0.0001)$. They produced more errors deviated to the left, consistent with a "pseudoneglect effect" (Bowers and Heilman, 1980). Here again, no effect of MPS, Sex or Handedness $\times$ Sex interaction was found on response spatial bias $(F(5,286)=0.9, p=0.4)$.

\subsection{Asymmetrical brain patterns of language and spatial tasks}

\subsubsection{Language production}

As illustrated in Fig. 1A, covert sentence production (PROD ${ }_{\text {SENT }}$ $v s$. Baseline) showed large leftward asymmetries in the frontal lobe including the precentral gyrus, and the opercular, triangular and orbital parts of the inferior frontal gyrus. In the parietal lobe, leftward asymmetries were found in the supramarginal gyrus extending to the posterior part of the superior temporal gyrus, as well as in the intraoccipital sulcus. Rightward asymmetry was found in the temporal sulcus and the calcarine fissure.

When covert sentence production was compared to the covert articulation of list of word ( PROD $_{\text {SENT }} v s$. PROD $_{\text {LIST }}$ ), the location of leftward asymmetries was almost identical in the frontal lobe (except for the precentral gyrus where leftward asymmetry was canceled out by the reference task) while leftward asymmetries were still detected along the superior temporal sulcus, in the angular and supramarginal gyri. Note that restricted rightward asymmetries were located in the caudate nucleus, the anterior cingulate and in the depth of the posterior STS (not visible on Fig. 1A)

\subsubsection{Spatial attention}

As shown in Fig. 1B, line bisection judgment (LBJ vs. Baseline) revealed large rightward asymmetries in the frontal lobe, including the precentral gyrus, the inferior frontal gyrus (opercular, triangular and orbital parts), the inferior frontal sulcus, the superior frontal gyrus, and the median superior frontal gyrus. In the occipital lobe, large right lateralized activation encompassed the posterior calcarine fissure, the lingual and fusiform gyri and the lateral middle occipital gyrus (MOG). Rightward asymmetry was also found in the inferior occipito-temporal junction (OTJ) as well as in the middle and posterior parts of the superior temporal sulcus encompassing the temporo-parietal junction (TPJ). In the parietal lobe, rightward asymmetries were restricted to the posterior parietal cortex, in the precuneus and along the parieto-occipital sulcus. Leftward asymmetry was observed in the supplementary motor area (SMA) and the opercular part of the Rolandic area corresponding to the somatosensory aspects of the motor response. These regions were not part of the motor ROI used to parse out irrelevant activity arising from hand-related responses during LBJ task.

When compared to VGS (LBJ $v s$. VGS), the pattern of asymmetry was similar to LBJ vs. Baseline contrast, except within ventral areas including the occipito-temporal region, the posterior part of the superior temporal sulcus and TPJ which did not show increased rightward asymmetry during LBJ compared to VGS (Fig. 1B).

\subsection{HLI values}

Over the whole sample, the two tasks elicited a significantly lateralized activity, as shown by one sample $t$-tests, favoring the left hemisphere for language production $\left(\mathrm{PROD}_{\mathrm{SENT}}\right.$ vs. Baseline: $+34.7 \pm 29.1, \quad$ range $=[-57,+82], \quad t(292)=20.4, \quad p<0.0001 ;$ PROD $_{\text {SENT }}$ vs. PROD LIST: $+47.8 \pm 33.4$, range $=[-72,+86], t(292)=$ 24.5, $p<0.0001)$ and the right hemisphere for spatial attention (LBJ vs. Baseline: $-20.4 \pm 23.3$, range $=[-73,+48], \mathrm{t}(292)=-$ $14.9, p<0.0001$; LBJ vs. VGS: $-19.2 \pm 29.2$, range $=[-70,+53], t$ $(292)=-11.3 p<0.0001$, Fig. 2 for HLI distributions).

\subsubsection{Effect of control condition on language and spatial hemispheric} LIS

The ANCOVA analysis revealed a main effect of the Control condition $(F(1,1)=21.5 p<0.0001)$ and of Function $(F(1,1)=1580.0$ $p<0.0001)$ as well as a Control condition $\mathrm{x}$ Function interaction $(F$ $(1,1)=14.2 p=0.0001)$. Post-hoc $t$-tests indicated that for language, contrasting a sentence production to a high-level control condition $\left(\right.$ PROD $\left._{\text {LIST }}\right)$ maximized the degree of leftward asymmetry as compared to baseline. By contrast, for spatial attention, the two HLIs were not significantly different (LBJ vs. Baseline: $-20.4 \pm 23.3$; LBJ vs. VGS: $-19.2 \pm 29.2, p>0.05)$.

According to these results, the following $\mathrm{LI}$ analyses will be

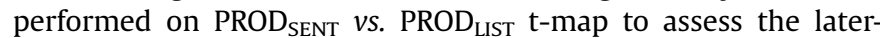
alization of language production. For spatial attention, although the difference was not significant between both LIs, we selected LBJ vs. Baseline t-map for which the rightward asymmetry was increased within the occipito-temporal region, as shown in the voxel-based functional asymmetry analysis. Hereafter, they will be referred as to PROD-HLI and LBJ-HLI for the hemispheric LI analyses, and PROD-Frontal-LI, LBJ-Frontal-LI and LBJ-Occ-LI for the regional analyses.

\subsubsection{Relationships between spatial attention, language production} LIs, MPS and spatial bias

3.3.2.1. Hemispheric LIs. The model of ANCOVA including MPS and Sex as between-subject variables, and PROD-HLI and spatial bias as within-subject factors, with a PROD-HLI $\times$ MPS interaction explained $12 \%$ of the variance $\left(R^{2}=0.12, F(7,285)=5.7, p<0.001\right)$, and the distribution of the residuals followed the Gaussian law (Shapiro-Wilk $W=1.0, p>0.05$ ). It returned an effect of PRODHLI $\left(F(1,1)=9.8, p=0.001\right.$, eta $\left.^{2}=0.03\right)$ on LBJ-HLI, together with an interaction between MPS $\times$ PROD-HLI $(F(2,2)=8.8, p=0.0001$, eta $\left.^{2}=0.05\right)$. As illustrated in Fig. 2 , this interaction indicated that only the SLH group showed a negative regression between LBJHLI and PROD-HLI (regression slope $=-8.7$, post-hoc $F(1-285)=$ $24.8 p<0.001$, Bonferroni-Holm adjusted $p$-value). The larger the HLI for spatial attention was lateralized to one hemisphere (i.e. right hemisphere), the larger the HLI for language production was 
A
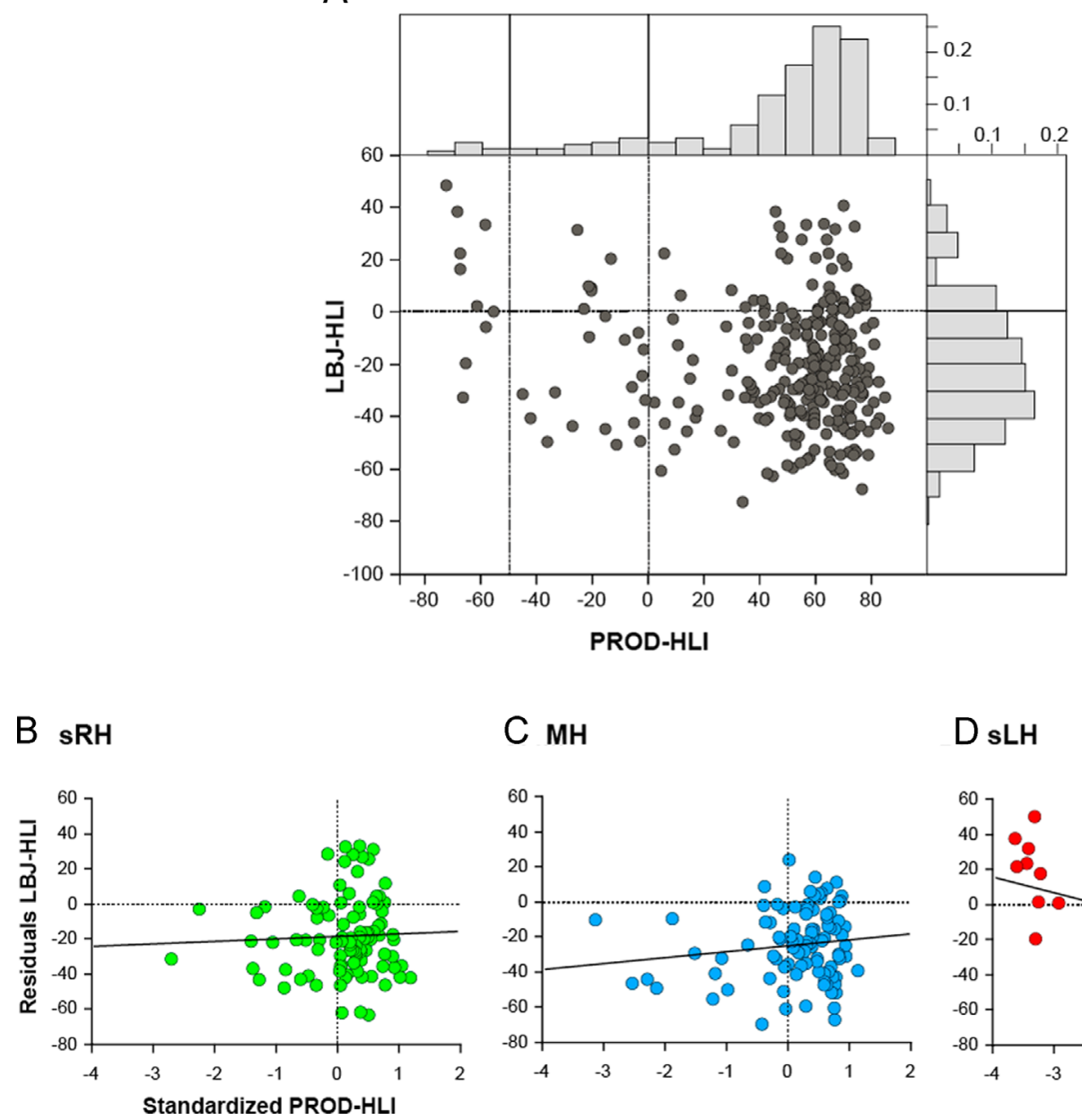

$\mathrm{C} \mathrm{MH}$

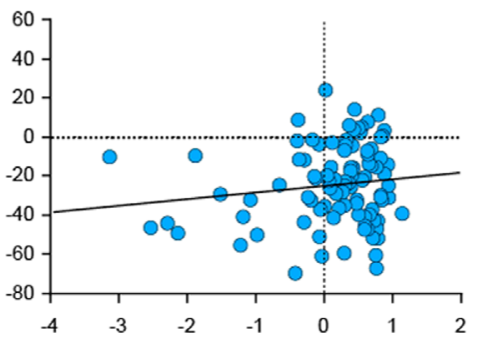

D sLH

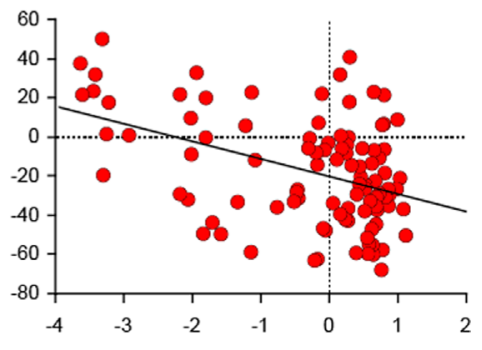

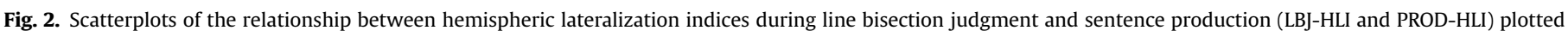

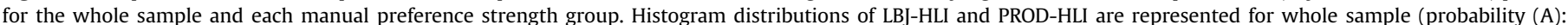

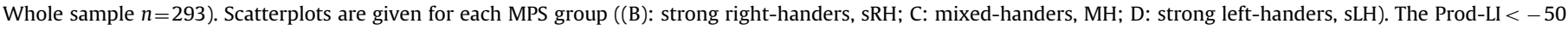
cut off point symbolized by a dashed line is given to indicate atypical rightward language lateralized subjects.

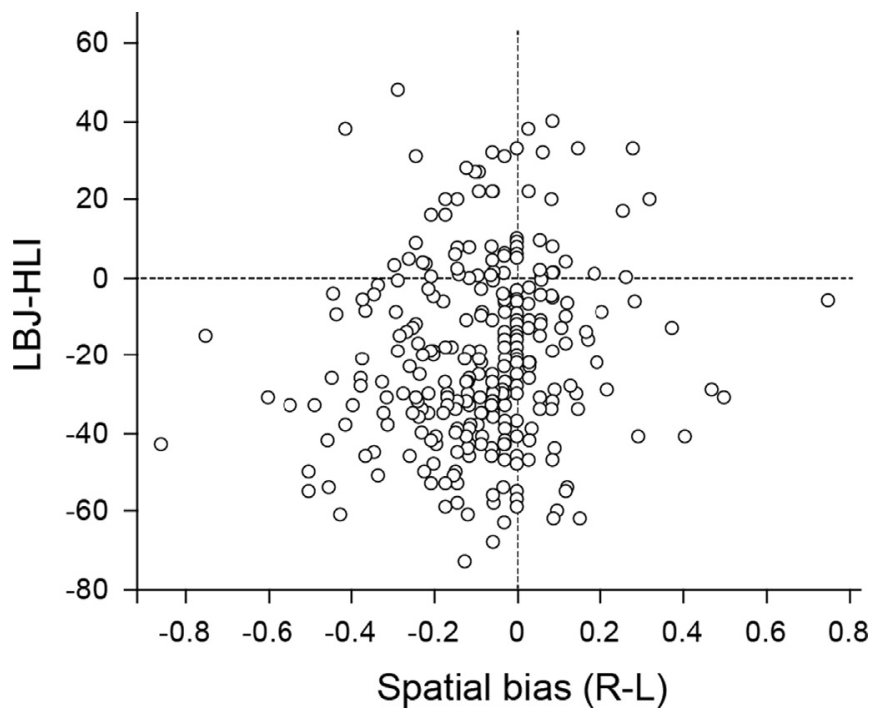

Fig. 3. Scatterplot of the relationship between hemispheric lateralization indices during line bisection judgment (LBJ-HLI) and behavioral spatial response bias. Positive correlation between LBJ-HLI and spatial bias $(t=2.2, p=0.02)$.

lateralized to the other hemisphere (i.e. left hemisphere). For the two other groups, there was no regression between spatial and language HLIs (sRH: slope $=2.2, F(1-285)=0.4, p=0.5 ; \mathrm{MH}$ : slope $=3.4, F(1-285)=1.4, p=0.4$, Bonferroni-Holm adjusted $p$ values). Post-hoc pairwise comparisons indicated that the slope of regression of sLH was different to the one of sRH (sLH vs. sRH: $F(1-285)=8.6, p=0.007$ ) and the one of $\mathrm{MH}$ (sLH vs. MH: $F$ $(1-285)=13.0, p=0.001)$, these two latter being not different from each other (sRH vs. MH: $F(1-285)=0.08, p=0.77$, Bonferroni-Holm adjusted $p$-values). In addition, the ANOVA showed an effect of spatial response bias $\left(F(1,1)=4.9, p=0.02\right.$, eta ${ }^{2}=0.01$ ) with a positive correlation between LBJ-HLI and spatial bias ( $t$ $(285)=2.2, p=0.02$ ). As illustrated in Fig. 3, the larger the participants' leftward spatial bias, the larger the rightward hemispheric lateralization during LBJ. No effect of $\operatorname{Sex}(F(1,1)=2.4$, $p=0.11$ e eta $\left.^{2}=0.007\right)$ or $\operatorname{MPS}\left(F(2,1)=1.9, p=0.15\right.$, eta $\left.^{2}=0.01\right)$ was found.

3.3.2.2. Regional LIs. Within the frontal ROI, the ANCOVA revealed a main effect of PROD-Frontal-LI $(F(1,1)=11.1, \quad p<0.0009$, $\mathrm{eta}^{2}=0.03$ ) on LBJ-Frontal-LI, together with an interaction between MPS x PROD-Frontal-LI $\left(F(2,2)=3.3, p=0.03\right.$, eta $\left.{ }^{2}=0.02\right)$. As before, this interaction revealed that only the sLH group showed a negative regression between LBJ-LI and PROD-LI (regression slope $=-8.4$, post-hoc $F(1-285)=18.0 p<0.0001$, Bonferroni-Holm adjusted $p$-value), while for the two other groups, there was no regression between both LIs (sRH: slope $=-0.2, F$ $(1-285)=0.001, p>1 ; \mathrm{MH}$ : slope $=0.8, F(1-285)=0.06, p>1$, Bonferroni-Holm adjusted $p$-values). Pairwise comparisons 
showed that the comparison of regression slopes was close to significance between sLH and $\mathrm{MH}(F(1-285)=5.3, p=0.06 ; \mathrm{MH}$ vs. sRH: $F(1-285)=0.03, p=0.85$; sRH vs. sLH: $F(1-285)=2.5$, $p=0.22$ ).

The ANCOVA also revealed a positive correlation between the spatial response bias and LBJ-LI values in the frontal ROI $(t(285)=$ $2.5, p=0.01$, eta $\left.^{2}=0.02\right)$. Finally, no main effect of $\operatorname{Sex}(F(1,1)=4.1$, $p>0.05$, eta $\left.{ }^{2}=0.01\right)$ or $\operatorname{MPS}\left(F(1,1)=1.3, p=0.2\right.$, eta $\left.^{2}=0.008\right)$ was found.

For the occipital ROI, the ANCOVA revealed a main effect of PROD-Frontal-LI $\left(F(1,1)=9.2, p=0.002\right.$, eta $\left.^{2}=0.03\right)$ together with an interaction between MPS $\times$ PROD-Frontal-LI $(F(2,2)=4.0$, $p=0.01$, eta ${ }^{2}=0.03$ ). Here again, only the sLH group showed a negative regression between LBJ-Occipital-LI and PROD-Frontal-LI (regression slope $=-7.7$, post-hoc $F(1-285)=15.0 p<0.0003$, Bonferroni-Holm adjusted $p$-values), while for the two other groups, there was no regression between the two LIs (sRH: slope $=-0.8, \quad F(1-285)=0.03, \quad p=0.8 ; \quad \mathrm{MH}: \quad$ slope $=3.3, \quad F$ $(1-285)=0.8, p=0.7$, Bonferroni-Holm adjusted $p$-value). Pairwise comparisons showed that the comparison of regression slopes was significant between sLH and $\mathrm{MH}(F(1-285)=7.4$, $p=0.02 ; \mathrm{MH}$ vs. sRH: $F(1-285)=0.5, p=0.5$; sRH vs. sLH: $F$ $(1-285)=1.7, p=0.4)$. Finally, no effect of spatial response bias $(F$ $(1,1)=0.9, \quad p=0.3, \quad$ eta $\left.{ }^{2}=0.003\right), \quad$ Sex $\quad(F(1,1)=0.01, \quad p=0.9$, $\left.\mathrm{eta}^{2}=0.00003\right)$, or MPS $\left(F(1,1)=1.5, p=0.2\right.$ eta $\left.^{2}=0.01\right)$ was found.

3.3.3. Effect of strong atypical language right dominant subjects on the relationship between spatial attention and language production LIS

3.3.3.1. Hemispheric LIs. Using Prod-HLI $<-50$ as a cut-off point, 10 individuals ( $9 \mathrm{sLH}$ and $1 \mathrm{MH}$ ) were found to be strongly right-lateralized for language production. Over these 10 subjects, the mean LBJ-HLI was positive $(9.7 \pm 26.0)$, although this leftward asymmetry was not significantly different to 0 ( $t$-test to $0 t(9)=1.2$, $p=0.2$ ). Without these 10 subjects, the ANCOVA performed on LBJHLI values showed that the regression between spatial bias and LBJ-HLI $\left(F(1,1)=3.9, p<0.04\right.$, eta $\left.^{2}=0.01\right)$ and the MPS $x$ PROD-HLI interaction $\left(F(2,2)=3.4, p<0.03\right.$, eta $\left.^{2}=0.02\right)$ remained significant. Post-hoc tests indicated a difference of regression slopes between sLH and $\mathrm{MH}$ (pairwise comparisons $F(1-275)=6.2, p=0.04$ ). The two other comparisons were not significant ( $\mathrm{MH} v$ s. $\mathrm{sRH}$ : $p=0.5$; sRH vs. sLH: $p=0.1$ Bonferroni-Holm adjusted $p$-values). Although still negative in $\mathrm{SLH}$, the regression slope was not different from 0 (regression slope $=-4.0, F(1-275)=3.8, p=0.1$ ) when the right language dominant sLH subjects were excluded. Finally, no effect of PROD-HLI on LBJ-HLI $\left(F(1,1)=0.003, p<0.9\right.$, eta $\left.^{2}=0.00001\right)$, Sex $\left(F(1,1)=2.7, p=0.09\right.$, eta $\left.{ }^{2}=0.009\right)$, or $\operatorname{MPS}(F(1,1)=1.8, p<0.1$, eta $^{2}=0.01$ ) was detected.

3.3.3.2. Regional LIs. Using Prod-Frontal-LI $<-50$ as a cut-off point, 11 individuals ( $10 \mathrm{sLH}$ and $1 \mathrm{MH}$ ) were found to be atypically right-lateralized for language production within the frontal cortex. For LBJ, the mean regional LBJ-LI was positive in the frontal ROI (LBJ-Frontal-LI: $7.4 \pm 33.0$ ) and in the occipital ROI (LBJ-Occ-LI: $14.6 \pm 17.2)$. For this latter ROI, the leftward asymmetry was significant (LBJ-Occ-LI: $t$-test to $0 t(10)=2.8, p=0.01$; LBJ-Frontal-LI: $t$ $(10)=0.7, p=0.4)$.

Within the frontal ROI, the ANCOVA did not reveal any effect or interaction, except a spatial bias effect on LBJ-Frontal-LI $(F(1,1)=$ $3.7, p=0.02$ eta $^{2}=0.02$ ) when the 11 strong atypicals are removed. By contrast, within the occipital ROI, the ANCOVA detected a close to significant PROD-Frontal-LI $\times$ MPS interaction effect $(F(2,2)=$ $2.7, p=0.06$ ) on LBJ-Occ-LI values, with a close to significant regression slopes difference between $\mathrm{MH}$ and $\operatorname{sLH}(F(1-274)=5.3$, $p=0.06)$ and a close to significant negative regression for $\mathrm{sLH}$ (regression slope $=-5.3, F(1-274)=5.2, p=0.06$ ).

\section{Discussion}

4.1. Complementary asymmetries for language and spatial attention are observed at the population level

Both language production and spatial attention tasks were successful in inducing consistent lateralized activation, as shown by the asymmetric brain patterns, the hemispheric and regional lateralization indices, favoring the left hemisphere for sentence production and the right hemisphere for spatial attention. Interestingly, even with an important number of left-handers, we did not observe any effect of manual preference on the lateralization of spatial attention during line bisection. The lack of significant difference between MPS groups is consistent with reports of a lack of relationship between handedness and lateralization for highorder spatial processes (Badzakova-Trajkov et al., 2010; Whitehouse and Bishop, 2009).

For sentence production, the most prominent leftward asymmetries were found in the frontal lobe, including the inferior frontal gyrus and the precentral gyrus, as well as in the posterior temporal areas and angular gyrus. All these regions have been related to the high-level semantic and syntactical components of language processing (Mazoyer et al., 2014; Vigneau et al., 2006). During LBJ, rightward asymmetry was detected within several frontal, posterior parietal, temporal and occipital regions, supporting previous neuroimaging findings on the role of these regions in landmark tasks (Badzakova-Trajkov et al., 2010; Cai et al. 2013; Ciçek et al., 2009; Fink et al., 2000; Fink et al., 2001; Flöel et al., 2005; Jansen et al., 2004; Karnath and Rorden, 2012). These rightward asymmetries interested regions belonging to the dorsal frontoparietal network controlling for spatial attention, and the ventral attentional system involved in stimulus-driven reorienting of attention (Corbetta and Shulman, 2002; Shulman et al., 2010) and/or alerting/arousal (Robertson et al., 1998). Rightward asymmetries found in the posterior parietal cortex and MOG are in line with previous studies using tasks that required spatial judgments (Badzakova-Trajkov et al., 2011; Cai et al., 2013; Ciçek et al., 2009; Fink et al., 2001). In particular, the study of Rorden et al. (2006) showed that the maximum overlap of lesions of patients with deficits at the line bisection test as compared to unbiased line bisection patients is observed within posterior parieto-occipital cortex and MOG, and within the inferior frontal cortex. Finally, the right lateralization of the superior frontal cortex is consistent with a TMS study showing that stimulation over the right superior frontal region impairs the ability to shift spatial attention toward both hemifields (Duecker et al., 2013). The right asymmetric pattern of results supports a dominant role of the right hemisphere dorsal network in voluntary spatial attention.

Within the ventral network, important asymmetries were found within OTJ, TPJ and inferior frontal cortex. Interestingly, the difference between the two contrasts (LBJ vs. Baseline and LBJ vs, VGS) was limited to the TPJ regions, which did not exhibit rightward asymmetry when LBJ was compared to VGS (in red Fig. 1B). This result can be read in the light of our previous studies that demonstrated that VGS condition already elicited asymmetry within these ventral attentional areas (Petit et al., 2014, 2009). Finally, rightward asymmetries of medial and lateral frontal areas were also in line with previous studies, which have considered these regions as involved in the executive control of attention (Bush et al., 2000; Fan et al., 2002), probably linked here to the three choices of response during LBJ.

\subsection{Association between right hemisphere dominance and pseudoneglect}

The second finding of this study is the correlation between the 
degree of hemispheric lateralization and the behavioral attentional bias. In average, the subjects more frequently erroneously judged that the vertical segment was deviated to the left of the true bisection. This response bias can be related to the behavioral pseudoneglect effect observed during "paper and pencil" bisection task in neurologically normal subjects, where they systematically tend to make small left bisection error when bisecting horizontal lines (Brooks et al., 2014; Manning et al., 1990). Pseudoneglect has been traditionally associated with a right hemispheric dominance for spatial attention, by analogy to the performance of right-hemisphere impaired patients with left unilateral spatial neglect (Bowers and Heilman, 1980). Here, we show that the degree of cerebral lateralization during LBJ is correlated with the degree of pseudoneglect. Previous studies have found the association between cerebral lateralization and spatial bias. For example, Szczepanski and Kastner (2013) demonstrated that the functional asymmetry of the dorsal frontoparietal network is correlated to the spatial line bisection bias (Szczepanski and Kastner, 2013). Using EEG, Benwell et al. (2014) showed that a left bisection bias was associated with increased right hemispheric engagement of TPJ (Benwell et al., 2014). Finally, Thiebaut de Schotten et al. (2011) demonstrated, with diffusion tensor imaging (DTI), a correlation between the rightward asymmetry of the volume of the second branch of the superior longitudinal fasciculus (SLFI) connecting parietal and frontal regions and the pseudoneglect during the line bisection (Thiebaut de Schotten et al., 2011). Although the cerebral bases of the spatial bias remained to be determined, our study indicated that that this association between the degree of rightward lateralization and pseudoneglect observed at the hemispheric level, is found in the frontal lobe but not in the occipital lobe. This finding would suggest that the behavioral attentional response bias we recorded during the LBJ task should not merely be considered as a perceptual bias, but rather would reflect integrative aspects of spatial attention.

\subsection{Complementary but not associated in right- and mixed-handers}

The present study including 151 left-handers and 142 righthanders provided compelling evidence that the association between language and spatial lateralization is only found in a group of left-handers characterized by a strong manual preference. Except for this group of sLH, language and spatial asymmetries were not associated in the other subjects, including right-handers and subjects with a weak manual preference (194 subjects out of 293 subjects, see Fig. 2B and C). First of all, these results help to reconcile discrepant results found in the literature concerning the existence or not of a relation between HS for language and spatial attention. Furthermore, these findings indicate that the strength and the direction of manual preference is an important factor to take into account to investigate complementary HS (Ocklenburg et al. 2014a). The absence of correlation between language and spatial lateralization is consistent with previous fTCD studies showing no association, including only right-handers (Lust et al., 2011; Rosch et al., 2012) or not (Whitehouse and Bishop, 2009). Both the asymmetrical maps findings and the lack of correlation support the idea of the presence of a left hemisphere bias for language and the presence of a right hemisphere bias for visuospatial functions, and that the absence of correlation between these two biases would be in favor of independent sources at the origin of the complementary cerebral organization (Bryden, 1990). The potential sources of the left asymmetry for language processing have been largely investigated, contrarily to those of the righthemisphere bias for spatial functions. While it is accepted that the left-hemisphere bias for language processing is a multifactorial trait determined by several genetic and non-genetic factors, it is still unclear which genes and environmental factors determine individual language lateralization (for a review, Ocklenburg et al., 2014b).

\subsection{Association between language and spatial lateralization is ob- served only in strong left-handers}

The negative correlation found in SLH indicates an association between language and spatial attention lateralization (see Fig. 2D). This association was found when the LIs were calculated within the frontal lobes and between occipital-LI for LBJ and frontal-LI for language. A negative correlation has been previously observed between inferior frontal region for language and parietal region for landmark task in a sample of left-handers including left- and right-dominant language subjects (Cai et al., 2013). The study of Badzakova-Trajkov et al. (2010) also found a negative correlation between left-frontal lobe asymmetry for language and right-parietal asymmetry for landmark task on the sample of participants that included right- and left-handers (Badzakova-Trajkov et al., 2010). Interestingly, a close inspection of the scatterplot of the Fig. 2 (in their paper) suggests that this correlation could be due to left-handers. To assess this effect, we reanalyzed their dataset given in supporting information. Applying our MPS categorization to their sample of 155 participants, 35 individuals were then categorized as SLH, 64 as $\mathrm{MH}$ and 56 as sRH. We regressed the rightparietal lobe LI by the left-frontal lobe LI, in function of MPS, and found a negative correlation between both LIs only for SLH (non parametric Spearman test, rho $=-0.4 ; p=0.01$ corrected for multiple comparisons). For the two other groups, the correlation was not significant $(\mathrm{MH}$ : rho $=-0.1 ; p=0.3$; sRH: rho $=-0.02$; $p=0.9$ ). Consequently, strong left-handers constitute a specific population where language and spatial HS are associated. The question is why this relationship is found in strong left-handed individuals? As shown by Cai et al. (2013) and Mazoyer et al. (2014), strong left-handed group gathered most of the individuals with atypical right-hemisphere language dominance. According to the causal hypothesis, two strong predictions can be put forward. First, an individual with atypical right language dominance should simultaneously manifest left spatial dominance. In other words, the sole atypical pattern of HS consists in a mirror-reversed pattern. It was indeed the case in Cai's study (2013), since all atypically right-lateralized language left-handers subjects in frontal ROI were atypically left-lateralized in parietal ROI during landmark task, while all (except one) typically left-lateralized for language were typically right-lateralized for spatial function. Second, the correlation between both lateralized functions should be due to mirror-reversed subjects. In the present study, the results did not fulfill these two strong predictions of the causal hypothesis(Fig. 4).

As concern the first one, we observed, in SLH, all different types of atypical complementary patterns of HS, albeit in different proportions. Interestingly, the observation of $\mathrm{RH}$ co-lateralization of language and spatial functions in healthy participants raises the question of the hemispheric crowding hypothesis (Teuber, 1974, Kosslyn, 1987), which states that visuospatial performance can be crowded out if language involves regions in the same hemisphere. The crowding hypothesis originates from neurological studies with patients with early left-hemisphere lesions, in whom atypical (right-hemisphere) language laterality was accompanied by a greater impairment in nonverbal than verbal skills (Lidzba et al., 2006). Thus, associated lateralization of language and spatial functioning in the right hemisphere affects non-verbal abilities. In healthy subjects, previous studies showed discrepant results. Using fTCD, Lust et al. (2011) showed that people with typical lateralized pattern (left for language and right for spatial) performed better than people showing bilateral representation for one or either function or both functions lateralized to the same hemisphere only when carrying out a dual-task. Other fTCD studies 

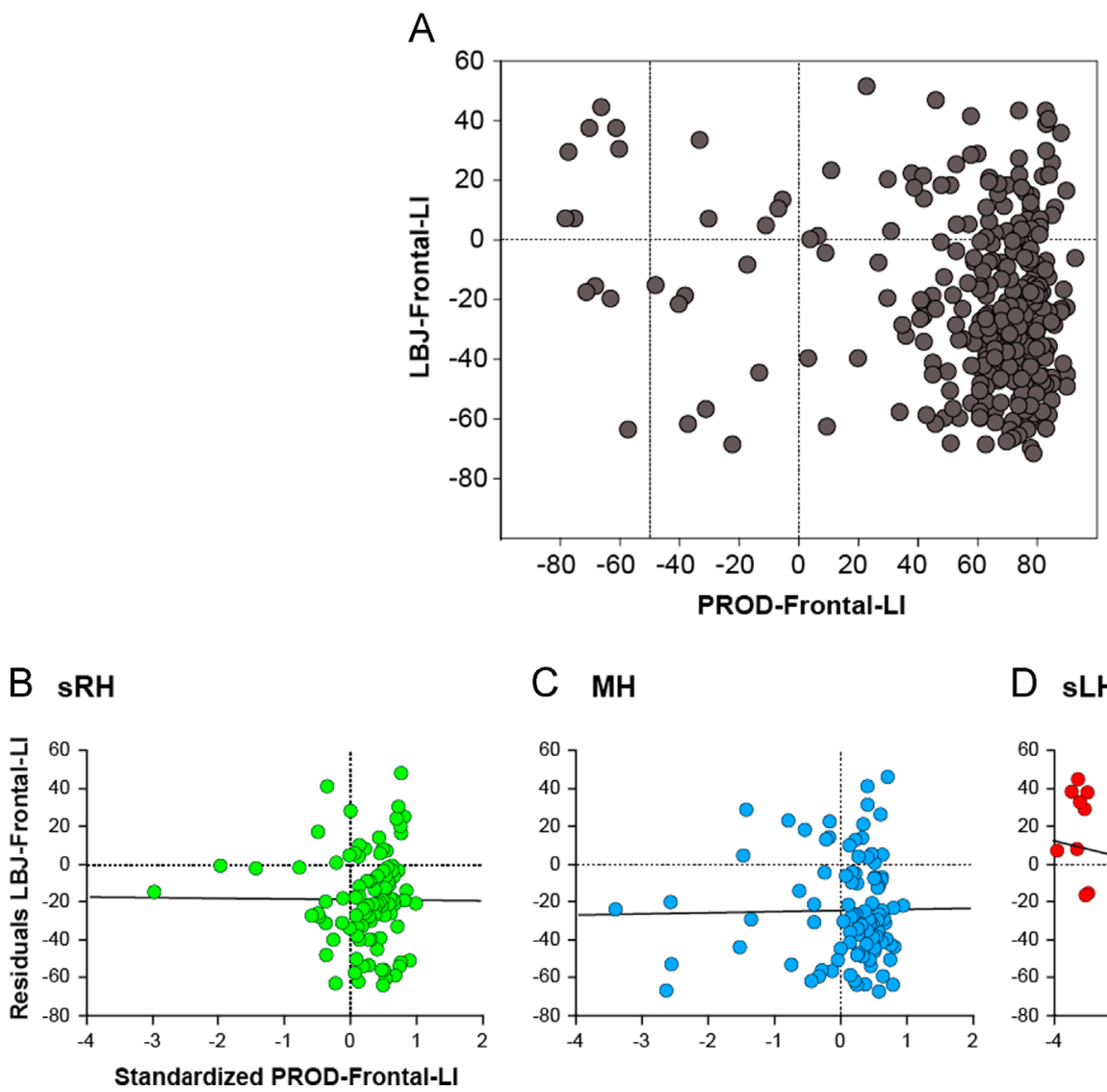

C $\mathrm{MH}$

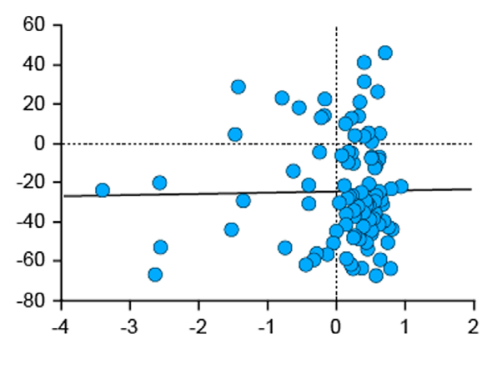

D sLH

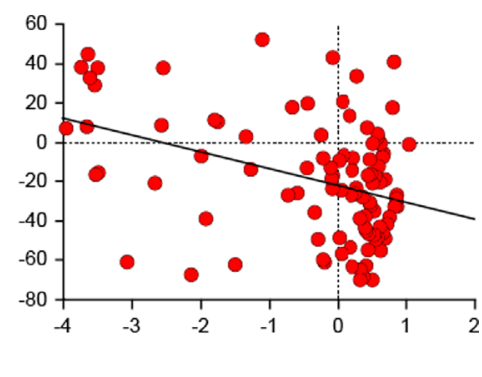

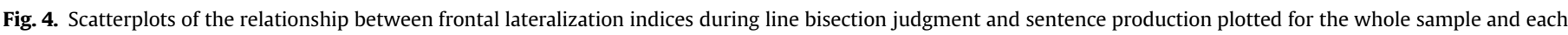

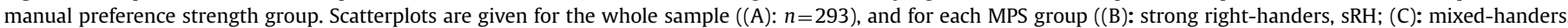

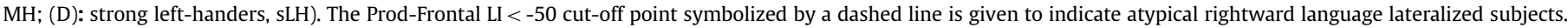

have found that all patterns of lateralization occur in healthy adults without any obvious cognitive disadvantages (Flöel et al., 2001, 2005; Whitehouse and Bishop 2009; Rosch et al., 2012). Further investigations are now needed to compare individual cognitive performance available in the BIL\&GIN database (Mazoyer et al., 2015), according to the different patterns of HS. In addition, our results suggest that, the proportion of atypical HS patterns varied depending on the ROI in which laterality index were correlated. For example, when the correlation was performed between different ROIs (occipital ROI for LBJ and frontal ROI for SENT), most of the atypical sLH subjects was considered as mirrorreversed (Fig. 5D), which was consistent with Cai's results (2013). By contrast, when the correlation was performed within the frontal ROI, we found subjects exhibiting a RH co-lateralization (Fig. 4D). These findings suggest that the categorization of an individual in a specific pattern of HS is somehow linked to the cerebral regions at work during the cognitive task. The transition from a hemispheric level to a regional level will give a finergrained understanding of the contribution of each cerebral region to the hemispheric patterns of cerebral organization.

As concern the second prediction, we found that the correlation between language and spatial lateralization at the hemispheric level, was not exclusively due to these right language atypical subjects, since the association remained significant when atypicals are removed. Interestingly, the fact that this interaction was still present between LBJ-Occipital and SENT-Frontal but not within the frontal lobe, suggest that the contribution of each region to the pattern of HS needs to be further explored.

Finally, an important issue is to reveal the mechanisms responsible for this relation between language and spatial lateralization in SLH. The causal perspective suggests causal mechanisms at the origin of the complementary HS, with right hemisphere dominance for spatial functions as a consequence of left-hemispheric involvement with language. However, the correlation that we observed in sLH does not imply causality. In other words, the association found between the strength and direction of verbal and spatial lateralization does not give any information about the existence of a causal relationship between language and spatial functions. The corpus callosum (CC) is the major support for hemispheric specialization, as has been demonstrated by the investigation of split-brain patients (Gazzaniga, 2000); this large bundle of fibers mediates both exchange of information and inhibition (van der Knaap and van der Ham, 2011). One characteristic of CC connectivity at the macroscopic level is its spatial organization, as it connects cortical regions in mirroring (homotopic) areas across hemispheres (Chao et al., 2009). Cook (1984) suggested that a homotopic callosal inhibition mechanism would be at the origin of the division between hemispheres of complementary functions. The inhibition of homologous activation would act to facilitate functional asymmetry and the lateralization of the brain. Here, we hypothesize that this correlation between language and spatial lateralization might reflect such a mechanism. In sLH that is a group that exhibits a large variability in the patterns of HS, this mechanism would be still active to maintain complementarity of functions between hemispheres. By contrast, in the majority of the population, this mechanism may have been active across development to set up a stable complementary pattern of functions and does not need to be at play anymore. To further explore this hypothesis, the use of a homotopic-based approach will be fruitful to explore the functional lateralization patterns and the inter-hemispheric organization of functional complementary specialization according to manual preference strength. 

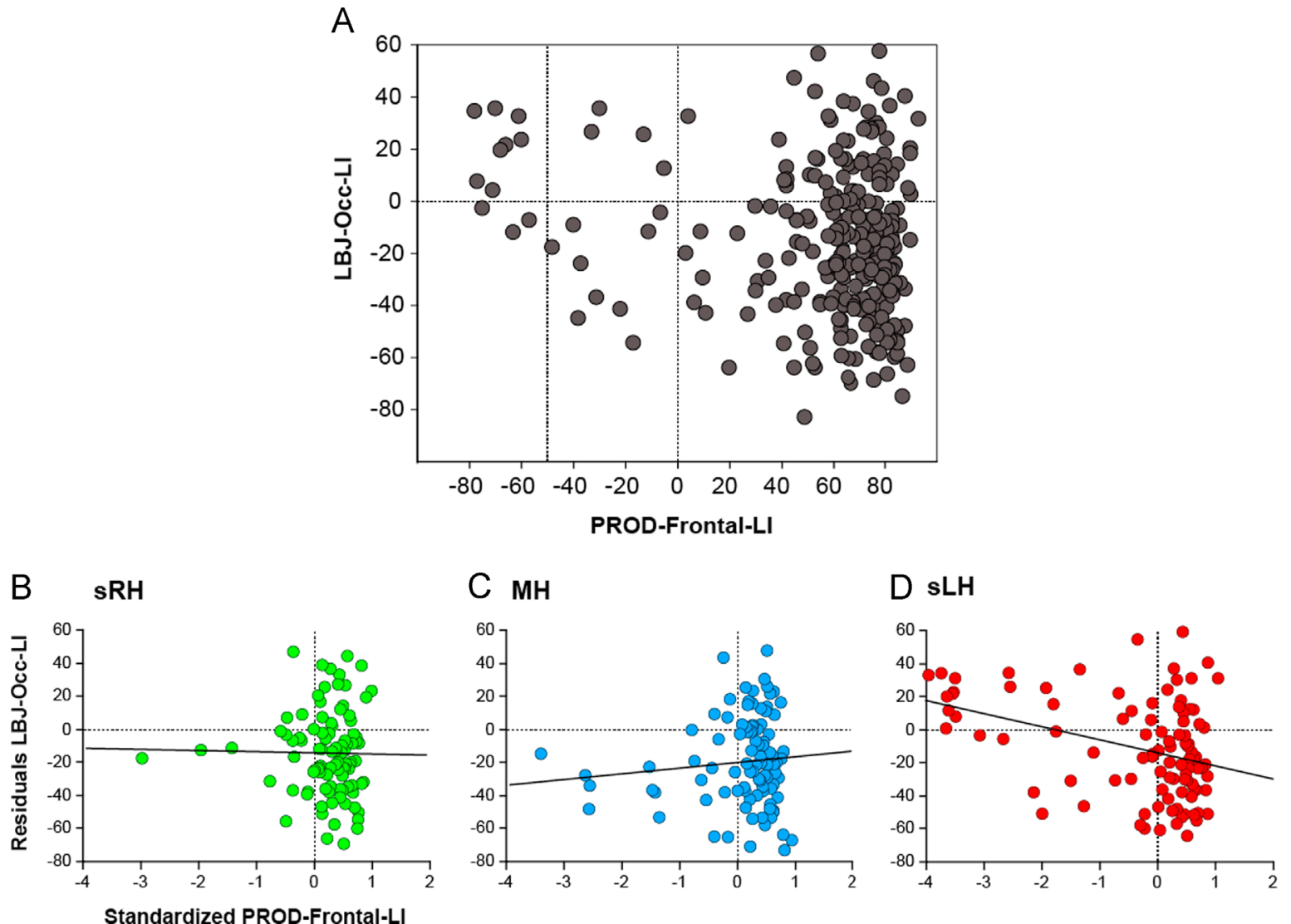

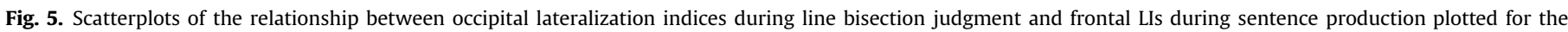
whole sample and each manual preference strength group.

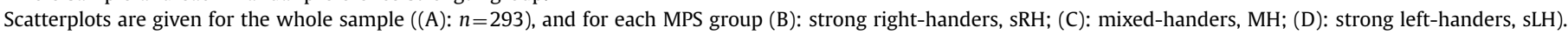
The Prod-Frontal $\mathrm{LI}<-50$ cut-off point symbolized by a dashed line is given to indicate atypical rightward language lateralized subjects.

\section{Conclusion}

The main findings of the present study demonstrate the existence of different patterns of HS varying across individuals, and that the association of language and spatial complementary HS is dependent of manual preference strength. To validate the hypothesis that it is related to the corpus callosum functioning, future investigations on inter-hemispheric organization using a resting-state intrinsic connectivity approach would be useful to explore the mechanisms that control cerebral lateralization. Furthermore, the variability of the patterns of HS raises the question of the relationships between cerebral lateralization patterns and cognitive performance.

\section{References}

Badzakova-Trajkov, G., Häberling, I.S., Corballis, M.C., 2011. Magical ideation, creativity, handedness, and cerebral asymmetries: a combined behavioural and fMRI study. Neuropsychologia 49, 2896-2903. http://dx.doi.org/10.1016/j. neuropsychologia.2011.06.016.

Badzakova-Trajkov, G., Häberling, I.S., Roberts, R.P., Corballis, M.C., 2010. Cerebral asymmetries: complementary and independent processes. Plos One 5 (3), e9682. http://dx.doi.org/10.1371/journal.pone.0009682.

Benwell, C.S., Thut, G., Grant, A., Harvey, M., 2014. A rightward shift in the visuospatial attention vector with healthy aging. Front. Aging Neurosci. 6, 113. http://dx.doi.org/10.3389/fnagi.2014.00113.

Bowers, D., Heilman, K.M., 1980. Pseudoneglect: effects of hemispace on a tactile line bisection task. Neuropsychologia 18 (4-5), 491-498.

Brooks, J.L., Della Sala, S., Darling, S., 2014. Representational pseudoneglect: a review. Neuropsychol. Rev. 24 (2), 148-165. http://dx.doi.org/10.1007 s11065-013-9245-2.

Bryden, M., 1990. Choosing sides: the left and right of the normal brain. Can.
Psychol. 31 (4), 297-309.

Bryden, M.P., Hécaen, H., DeAgostini, M., 1983. Patterns of cerebral organization. Brain Lang. 20 (2), 249-262.

Bush, G., Luu, P., Posner, M.I., 2000. Cognitive and emotional influences in anterior cingulate cortex. Trends Cognit. Sci. 4 (6), 215-222.

Cai, Q., Van der Haegen, L., 2015. What can atypical language hemispheric specialization tell us about cognitive functions? Neurosci. Bull. 31 (2), 220-226. http: //dx.doi.org/10.1007/s12264-014-1505-5.

Cai, Q., Van der Haegen, L., Brysbaert, M., 2013. Complementary hemispheric specialization for language production and visuospatial attention. Proc. Natl. Acad. Sci. USA 110 (4), 322-330. http://dx.doi.org/10.1073/pnas.1212956110.

Chao, Y.P., Cho, K.H., Yeh, C.H., Chou, K.H., Chen, J.H., Lin, C.P., 2009. Probabilistic topography of human corpus callosum using cytoarchitectural parcellation and high angular resolution diffusion imaging tractography. Hum. Brain Mapp. 30 (10), 3172-3187. http://dx.doi.org/10.1002/hbm.20739.

Ciçek, M., Deouell, L.Y., Knight, R.T., 2009. Brain activity during landmark and line bisection tasks. Front. Hum. Neurosci. 3, 7. http://dx.doi.org/10.3389/ neuro.09.007.2009.

Cook, N.D., 1984. Homotopic callosal inhibition. Brain and Lang. 23 (1), 116-125. http://dx.doi.org/10.1016/0093-934X(84)90010-5.

Corballis, M.C., 2009. The evolution and genetics of cerebral asymmetry. Philos. Trans. R. Soc. Lond. Ser. B, Biol. Sci. 364 (1519), 867-879. http://dx.doi.org/ 10.1098/rstb.2008.0232.

Corbetta, M., Shulman, G.L., 2002. Control of goal-directed and stimulus-driven attention in the brain. Nat. Rev. Neurosci. 3 (3), 201-215. http://dx.doi.org/ $10.1038 / \mathrm{nrn} 755$.

Dorst, J., Haag, A., Knake, S., Oertel, W.H., Hamer, H.M., Rosenow, F., 2008. Functional transcranial doppler sonography and a spatial orientation paradigm identify the non-dominant hemisphere. Brain Cogn. 68 (1), 53-58. http://dx. doi.org/10.1016/j.bandc.2008.02.123.

Duecker, F., Formisano, E., Sack, A.T., 2013. Hemispheric differences in the voluntary control of spatial attention: Direct evidence for a right-hemispheric dominance within frontal cortex. J. Cognit. Neurosci. 25, 1332-13342. http://dx.doi.org/ 10.1162/jocn_a_00402.

Dym, R.J., Burns, J., Freeman, K., Lipton, M.L., 2011. Is functional MR imaging assessment of hemispheric language dominance as good as the wada test? Meta -Anal. Radiol. 261 (2), 446-455. http://dx.doi.org/10.1148/radiol.11101344.

Fan, J., McCandliss, B.D., Sommer, T., Raz, A., Posner, M.I., 2002. Testing the efficiency and independence of attentional networks. J. Cognit. Neurosci. 14 (3), 
340-347. http://dx.doi.org/10.1162/089892902317361886.

Fink, G.R., Marshall, J.C., Shah, N.J., Weiss, P.H., Halligan, P.W., Grosse-Ruyken, M. Freund, H.J., 2000. Line bisection judgments implicate right parietal cortex and cerebellum as assessed by fmri. Neurology 54 (6), 1324-1331.

Fink, G.R., Marshall, J.C., Weiss, P.H., Zilles, K., 2001. The neural basis of vertical and horizontal line bisection judgments: an fmri study of normal volunteers. NeuroImage 14 (1), S59-S67. http://dx.doi.org/10.1006/nimg.2001.0819.

Flöel, A., Jansen, A., Deppe, M., Kanowski, M., Konrad, C., Sommer, J., Knecht, S., 2005. Atypical hemispheric dominance for attention: functional MRI topography. J. Cereb. Blood Flow. Metab. 25 (9), 1197-1208. http://dx.doi.org/ $10.1038 /$ sj.jcbfm.9600114.

Flöel, A., Knecht, S., Lohmann, H., Deppe, M., Sommer, J., Dräger, B., Henningsen, H., 2001. Language and spatial attention can lateralize to the same hemisphere in healthy humans. Neurology 57 (6), 1018-1024.

Gazzaniga, M.S., 2000. Cerebral specialization and interhemispheric communication: does the corpus callosum enable the human condition? Brain: J. Neurol. 123, 1293-1326.

Hervé, P.-Y., Zago, L., Petit, L., Mazoyer, B., Tzourio-Mazoyer, N., 2013. Revisiting human hemispheric specialization with neuroimaging. Trends Cognit. Sci. 17 (2), 69-80. http://dx.doi.org/10.1016/j.tics.2012.12.004.

Hopkins, W.D., Cantalupo, C., 2008. Theoretical speculations on the evolutionary origins of hemispheric specialization. Curr. Dir. Psychol. Sci. 17 (3), 233-237.

Hutsler, J.J., Gillespie, M.E., Gazzaniga, M.S., 2002. The evolution of hemispheric specialization. In: Bizzi, E., Caliassano, P., Volterra, V. (Eds.), Frontiers of Life: The Intelligent Systems 3. Academic, New York, pp. 37-49.

Jansen, A., Flöel, A., Deppe, M., van Randenborgh, J., Dräger, B., Kanowski, M., Knecht, S., 2004. Determining the hemispheric dominance of spatial attention: a comparison between ftcd and fmri. Hum. Brain Mapp. 23 (3), 168-180. http: //dx.doi.org/10.1002/hbm.20055.

Karnath, H.O., Rorden, C., 2012. The anatomy of spatial neglect. Neuropsychologia 50 (6), 1010-1017. http://dx.doi.org/10.1016/j.neuropsychologia.2011.06.027.

Kosslyn, S.M., 1987. Seeing and imagining in the cerebral hemispheres: a computational approach. Psychol. Rev. 94 (2), 148-175.

Lidzba, K., Staudt, M., Wilke, M., Krägeloh-Mann, I., 2006. Visuospatial deficits in patients with early left-hemispheric lesions and functional reorganization of language: consequence of lesion or reorganization? Neuropsychologia 44 (7) 1088-1094.

Lust, J.M., Geuze, R.H., Groothuis, A.G., Bouma, A., 2011. Functional cerebral lateralization and dual-task efficiency-testing the function of human brain lateralization using fTCD. Behav. Brain Res. 217 (2), 293-301. http://dx.doi.org/ 10.1016/j.bbr.2010.10.029.

Manning, L., Halligan, P.W., Marshall, J.C., 1990. Individual variation in line bisection: a study of normal subjects with application to the interpretation of visual neglect. Neuropsychologia 28 (7), 647-655.

Mazoyer, B., Mellet, E., Perchey, G., Zago, L., Crivello, F., Jobard, G., Tzourio-Mazoyer, N., 2015. BIL\&GIN: a neuroimaging, cognitive, behavioral, and genetic database for the study of human brain lateralization. NeuroImage . http://dx.doi.org/ 10.1016/j.neuroimage.2015.02.071.

Mazoyer, B., Zago, L., Jobard, G., Crivello, F., Joliot, M., Perchey, G., Tzourio-Mazoyer, N., 2014. Gaussian mixture modeling of hemispheric lateralization for language in a large sample of healthy individuals balanced for handedness. Plos One 9 (6), e101165. http://dx.doi.org/10.1371/journal.pone.0101165.

Ocklenburg, S., Hirnstein, M., Beste, C., Güntürkün, O., 2014a. Lateralization and cognitive systems. Front. Psychol. 5, 1143. http://dx.doi.org/10.3389/ fpsyg.2014.01143.

Ocklenburg, S., Beste, C., Arning, L., Peterburs, J., Güntürkün, O., 2014b. The ontogenesis of language lateralization and its relation to handedness. Neurosci. Biobehav. Rev. 43, 191-198.

Oldfield, R.C., 1971. The assessment and analysis of handedness: the edinburgh inventory. Neuropsychologia 9 (1), 97-113.
Petit, L., Zago, L., Mellet, E., Jobard, G., Crivello, F., Joliot, M., Tzourio-Mazoyer, N., 2014. Strong rightward lateralization of the dorsal attentional network in lefthanders with right sighting-eye: an evolutionary advantage. Hum. Brain Mapp. 36, 1151-1164. http://dx.doi.org/10.1002/hbm.22693.

Petit, L., Zago, L., Vigneau, M., Andersson, F., Crivello, F., Mazoyer, B., Tzourio-Mazoyer, N., 2009. Functional asymmetries revealed in visually guided saccades: an FMRI study. J. Neurophysiol. 102 (5), 2994-3003. http://dx.doi.org/10.1152/ jn.00280.2009.

Powell, J.L., Kemp, G.J., García-Finaña, M., 2012. Association between language and spatial laterality and cognitive ability: an fmri study. NeuroImage 59 (2), 1818-1829. http://dx.doi.org/10.1016/j.neuroimage.2011.08.040.

Robertson, I.H., Mattingley, J.B., Rorden, C., Driver, J., 1998. Phasic alerting of neglect patients overcomes their spatial deficit in visual awareness. Nature 395 (6698), 169-172. http://dx.doi.org/10.1038/25993.

Rorden, C., Fruhmann Berger, M., Karnath, H.O., 2006. Disturbed line bisection is associated with posterior brain lesions. Brain Res. 1080, 17-25. http://dx.doi. org/10.1016/j.brainres.2004.10.071.

Rosch, R.E., Bishop, D.V., Badcock, N.A., 2012. Lateralised visual attention is unrelated to language lateralisation, and not influenced by task difficulty-A functional transcranial doppler study. Neuropsychologia 50 (5), 810-815. http: //dx.doi.org/10.1016/j.neuropsychologia.2012.01.015.

Shulman, G.L., Pope, D.L., Astafiev, S.V., McAvoy, M.P., Snyder, A.Z., Corbetta, M., 2010. Right hemisphere dominance during spatial selective attention and target detection occurs outside the dorsal frontoparietal network. J. Neurosci.: Off. J. Soc. Neurosci. 30 (10), 3640-3651. http://dx.doi.org/10.1523/ JNEUROSCI.4085-09.2010.

Szczepanski, S.M., Kastner, S., 2013. Shifting attentional priorities: control of spatial attention through hemispheric competition. J. Neurosci.: Off. J. Soc. Neurosci. 33 (12), 5411-5421. http://dx.doi.org/10.1523/JNEUROSCI.4089-12.2013.

Teuber, H.L., 1974. Why two Brains?. In: Schmitt, F., Worden, F. (Eds.), The Neurosciences: Third Study Program. MIT Press, Cambridge, MA, USA, pp. 71-74.

Thiebaut de Schotten, M., Dell'Acqua, F., Forkel, S.J., Simmons, A., Vergani, F., Murphy, D.G., Catani, M., 2011. A lateralized brain network for visuospatial attention. Nat. Neurosci. 14 (10), 1245-1246. http://dx.doi.org/10.1038/nn.2905.

Tzourio-Mazoyer, N., Landeau, B., Papathanassiou, D., Crivello, F., Etard, O., Delcroix, N., Joliot, M., 2002. Automated anatomical labeling of activations in SPM using a macroscopic anatomical parcellation of the MNI MRI single-subject brain. NeuroImage 15 (1), 273-289. http://dx.doi.org/10.1006/nimg.2001.0978.

Tzourio-Mazoyer, N., Petit, L., Zago, L., Crivello, F., Vinuesa, N., Joliot, M., Mazoyer, B., 2015. Between-hand difference in ipsilateral deactivation is associated with hand lateralization: FMRI mapping of 284 volunteers balanced for handedness. Front. Hum. Neurosci. 9, 5. http://dx.doi.org/10.3389/fnhum.2015.00005.

Vigneau, M., Beaucousin, V., Hervé, P.Y., Duffau, H., Crivello, F., Houdé, O., TzourioMazoyer, N., 2006. Meta-analyzing left hemisphere language areas: phonology, semantics, and sentence processing. NeuroImage 30 (4), 1414-1432. http://dx. doi.org/10.1016/j.neuroimage.2005.11.002.

Whitehouse, A.J., Bishop, D.V., 2009. Hemispheric division of function is the result of independent probabilistic biases. Neuropsychologia 47 (8-9), 1938-1943. http://dx.doi.org/10.1016/j.neuropsychologia.2009.03.005.

Wilke, M., Lidzba, K., 2007. LI-tool: a new toolbox to assess lateralization in functional mr-data. J. Neurosci. Methods 163 (1), 128-136. http://dx.doi.org/ 10.1016/j.jneumeth.2007.01.026.

Wilke, M., Schmithorst, V.J., 2006. A combined bootstrap/histogram analysis approach for computing a lateralization index from neuroimaging data. NeuroImage 33 (2), 522-530, http://dx.doi.org/10.1016/j.neuroimage.2006.07.010.

Willems, R.M., Van der Haegen, L., Fisher, S.E., Francks, C., 2014. On the other hand: including left-handers in cognitive neuroscience and neurogenetics. Nat. Rev. Neurosci. 15 (3).

van der Knaap, L.J., van der Ham, I.J., 2011. How does the corpus callosum mediate interhemispheric transfer? A review. Behav. Brain Res. 223, 211-221. 